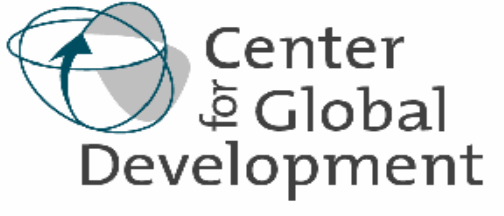

\author{
Working Paper Number 78 \\ January 2006
}

Governance and Corruption in

Public Health Care Systems

By Maureen Lewis

\begin{abstract}
What factors affect health care delivery in the developing world? Anecdotal evidence of lives cut tragically short and the loss of productivity due to avoidable diseases is an area of salient concern in global health and international development. This working paper looks at factual evidence to describe the main challenges facing health care delivery in developing countries, including absenteeism, corruption, informal payments, and mismanagement. The author concludes that good governance is important in ensuring effective health care delivery, and that returns to investments in health are low where governance issues are not addressed.
\end{abstract}

The Center for Global Development is an independent think tank that works to reduce global poverty and inequality through rigorous research and active engagement with the policy community. This Working Paper was made possible in part by funding from the William and Flora Hewlett Foundation.

Use and dissemination of this Working Paper is encouraged, however reproduced copies may not be used for commercial purposes. Further usage is permitted under the terms of the Creative Commons License. The views expressed in this paper are those of the author and should not be attributed to the directors or funders of the Center for Global Development.

www.cgdev.org 


\title{
Governance and Corruption in Public Health Care Systems
}

\author{
Maureen Lewis* \\ Senior Fellow \\ Center for Global Development
}

January 2006

* I am grateful to William Savedoff for extensive peer review comments and suggestions, and to James Habyarimana, John Hicklin, Randi Ryterman, Julian Schweitzer, Peter Heller and Adam Wagstaff for helpful comments on earlier drafts. John Vos, Sabeen Hasanalli, Shweta Jain, Anna Wong and Bilal Siddiqi provided able research assistance on the paper. Any remaining errors are my own. 
Institutions and governance have emerged as the back bone of development, and are increasingly being shown as critical to income levels (Rigobon and Rodrik, 2004; Rodrik, Subramanian and Trebbi, 2004; Kaufman and Kraay, 2002), fostering overall development (Kaufmann, Kraay and Mastruzzi, 2005), ensuring sound macroeconomic policies (IMF, 1997; Berg, 2005) and per capita income growth (World Bank, 2003b). The World Bank’s 2006 World Development Report looks again at the determinants of poverty and argues for an emphasis on equal opportunity and the institutional infrastructure (World Bank, 2006). The recent UK government's Report on the Commission for Africa places a premium on governance and institutions as complementary to other actions in bolstering development prospects in the region, and the US government's Millennium Challenge Corporation expects to spend billions of dollars on countries that demonstrate good governance. Thus both theory and empirical evidence is accumulating to place governance at the center of development thinking, spending and action.

At the same time the international community has pledged their support in helping countries reach a set of ambitious Millennium Development Goals (MDGs) that would sharply reduce poverty, raise educational levels and reduce mortality, among other achievements. The combination of the two threads suggests the need to ensure that institutional development is fostered in conjunction with efforts to accelerate progress on economic and social fronts.

Improving human capital in reaching the MDGs and raising living standards has led to a focus on investments in the social sectors, particularly education and health. These sectors received increasing attention and support from the multi-lateral and bi-lateral institutions over the past decade (IMF and World Bank, 2005). Reaching the MDGs in health will require adequate funding (United Nations Millennium Project, 2005; Commission on Macroeconomics and Health, 2001). However, it is equally important to ensure that health systems function so services can be delivered and health professionals be accountable to the public, government and, where they are providing funds, donors. The strategy to date emphasizes funding and need, with much less concern for effectiveness or, surprisingly, impact, and has largely neglected institutions and governance issues.

The problem with the lack of concern for basic governance principles in health care delivery is that well-intentioned spending may have no impact. Priorities cannot be met if institutions don't function and scarce resources are wasted. Bribes, corrupt officials and mis-procurement undermine health care delivery in much the same way they do for police services, law courts and customs whose functions become compromised by the culture of poor governance and corruption.

This paper examines health systems from the perspective of governance, drawing on the knowledge and experience garnered over the past decade at the national and firm levels and supplementing that with health-specific evidence. It therefore examines the effectiveness of government and specifically the efficiency of its role in producing health care services. 
The next section outlines the health care markets, the role of government and the definition and measurement of governance. The evidence from developing countries on various elements of governance and corruption in health care delivery is then reviewed, and the last two sections lay out policy possibilities and implications for the sector.

\section{Health Care Markets, Public Health Care Systems and Governance}

The growth, governance and corruption literature (Elliott, 1997; Transparency International, 2005; World Bank, 1997; Commission for Africa, 2005) largely ignores governance when it comes to public policies in the social sectors. Implicit in that neglect is that good intentions surrounding these investments are such that governance is secondary, if it has any importance at all. Efficiency in resource use would suggest the need to consider such themes, however.

\section{A. Characteristics of Health Care Markets}

Unlike other goods and services health care services embody some unique characteristics stemming from inherent market failures. First is the asymmetry of information and agency challenge of physicians acting as agents for patients. Patients are aware they don't feel well but they rely on health professionals, often physicians, to act as their agents in diagnosing and treating ailments. Patients are ill-equipped to assess the adequacy and quality of physician decisions and actions, and therefore focus on the environmental and interpersonal aspects of clinical services, the elements they are best able to evaluate.

Second, adverse selection practices by private health insurers lead to an uninsured population disproportionately made up of those most in need of health care: the chronically ill, the poor and those having experienced a catastrophic illness. In settings without health insurance ability to pay limits the same groups from obtaining care so the same constraints apply. Government intervention compensates for the market's reluctance to insure the most vulnerable. And because of the random nature of illness or injury, government subsidies protect the population against financial demands of illness.

Finally, the moral hazard of over-consumption by the insured who do not face the true cost of health care requires active cost containment, the key issue for OECD countries and relevant for development countries as well. A second form of moral hazard is the over production of care by physicians when third parties cover costs. Physician induced demand drives costs in much the same way that consumer behavior does, with similar implications for payers.

In most countries market failures translate into publicly financed and delivered care, and/or regulation from public and private bodies. Most developing countries depend heavily on public intervention rather than regulation, hence the predominance of public health care systems in those countries. 
A limitation in assessing existing health care systems is the lack of any single measure of what constitutes a functioning system. Every OECD country has its own, unique health care arrangements with a mix of public and private financing, delivery and regulations. OECD comparisons of system performance tend to be limited to gross measures such as spending levels or mortality statistics. The more meaningful comparisons are those based on specific diseases where costs, treatment options and outcomes can be compared, though countries don't necessarily collect comparable data limiting the extent of meaningful comparisons. For developing countries systems differ and information on comparable indicators simply do not yet exist.

These characteristics explain why government's role is so critical to examine, and why the indicators used in this paper for health care delivery are so different from those used in other studies of governance or health care delivery. This effort documents "government failure" to live up to the objectives of public policy, looking specifically at efficiency enhancement and redistribution, and focusing on incentives as a means to improve performance without compromising equity objectives (Jack and Lewis, 2004).

\section{B. Producing Public Health Care: a Framework}

The production function represents the core of public health care systems embodying capital and labor and governance. A simple representation is the following:

Health Outcomes $=(\mathrm{L}, \mathrm{K}, \mathrm{G})$

where governance represents some measure of institutional quality or governance. Increases in labor and capital can improve outcomes, but $\mathrm{G}$ may dampen or enhance these effects.

Labor encompasses management, physicians, nurses, other medical staff. Capital is made up of infrastructure, equipment and other fixed assets, as well as financing: government transfers for local purchase, in-kind provision of drugs and supplies, and third party and consumer payments. The functioning of the public system is determined by the incentives facing the actors in the system, the manner in which inputs are managed and the accountability imbedded in the incentive structure.

While straightforward in concept, the production function itself is far from simple and the market failures identified above plague both private and public systems (i.e., principal agent and information asymmetry problems), which undermine incentives and limit the extent of accountability. Accountability can be to a central government, local government, communities or patients, or some combination of these.

Measures to assess performance of public systems are lacking. Infant mortality, a readily available and commonly used measure of outcome, better reflects more aggregate measures of well being (such as income and education) rather than the health system, although once the IMR drops below 25-30 per 1000 it better captures the quality and 
extent of medical interventions. Monitoring basic functions such as hiring, existence of appropriate policies, purchase of drugs, building of clinics and procurement practices, can be easily accomplished but only represents the identification of inputs.

The more complex and important measures of health system performance are such things as staff output, drug and medical supply availability, regularity of funding transfers, state of physical infrastructure, inventory and functionality of equipment, and existence of patient records, factors which reflect whether health systems are meeting minimal efficiency and quality standards. Utilization data and patient satisfaction offer complementary metrics of health system effectiveness since under-utilized public facilities or their by-passing by target groups suggest implementation problems. Despite their relevance, such data rarely if ever are collected on a routine basis in developing countries. Indeed such information only exists for a subset of countries and often for only a segment of the health system. In the absence of comparable monitorable indicators this kind of information can inform policy makers about performance and the pressure points of health systems development before large scale data collection is in place.

\section{Governance and Corruption in Health Care Delivery}

Health care provision depends on efficiently combining financial resources, human resources, and supplies, and delivering services in a timely fashion distributed spatially throughout a country. This requires a "system" that mobilizes and distributes resources, processes information and acts upon it, and motivates providers' appropriate behavior by individuals, health care workers, and administrators. Good governance is a critical factor in making such a system function.

In health care, good governance implies that health care systems function effectively and with some level of efficiency. Though many governance indicators have been developed for countries in the aggregate, governance indicators for specific sectors, such as health, are not readily available. Consequently, it is necessary to look for proxies that reflect the quality of health sector governance. This paper will focus on one such proxy, evidence of corruption, that results when governance is poor. This section reviews the definition of corruption and its application to the health sector.

Sound institutions and good governance go hand-in-hand. Kaufman and Kraay (2003) define good governance as "the traditions and institutions by which authority in a country is exercised”. More specifically it encompasses:

- capacity of government to formulate and implement sound policies, manage resources and provide services efficiently;

- the process that allows citizens to select, hold accountable, monitor and replace government; and,

- the respect of government and citizens for the institutions that govern economic and social interaction. 
Multiple institutions collect indicators of governance. Kaufman, Kraay and Mastruzzi (2005) have boiled them down to six dimensions of governance: voice and accountability; political stability and lack of violence; government effectiveness; regulatory quality; rule of law; and, control of corruption -- all of which affect the environment within which health care services function. The robustness of the private sector in health will be affected by factors such as poor regulation or an ineffective court system, the elements of particular relevance to service delivery are voice and accountability, government effectiveness and control of corruption.

Voice and accountability reflect external accountability, the effectiveness of citizen and institutional influences on government action. While much of the broader concerns are with human rights, in health factors such as the viability of the political system, media independence and trust in government reflect the degree to which citizens can influence government decisions that affect them. For example, where local leaders are not elected, localities cannot hold public servants accountable for their decisions or actions, and public bodies have little incentive to effectively serve the community. The lack of voice leaves localities at the mercy of public sector whims. Voice and accountability permit communities to be involved in decisions and oversight of health care services.

Government effectiveness encompasses efficiency of the bureaucracy and public servants, roles and responsibilities of local and regional governments, including the administrative and technical skills of government, effectiveness of policy and program formulation, governing capacity, and effective use of resources. Extending the example above, decentralization that comes without funding or local authority undermines potential effectiveness of local jurisdictions as they have no power to affect resource allocations or decision-making and can be the victim of "provider capture" where centrally deployed staff determine service, organization and delivery.

Control of corruption is straightforward. It captures the extent and nature of corruption among public officials, including tracking the incidence of nepotism, cronyism and bribes among civil servants, irregularities in public purchasing and oversight, and the nature and extent to which government manages corruption.

Corruption can be defined as "use of public office for private gains" (Bardhan, 1997) or "the sale by government officials of government property for personal gain" (Shleifer and Vishny, 1993). With either definition good government hinges on the incentives for and accountability of public servants.

Forms of corruption vary. Sparrow (1996) describes the extent of fraud in the US Medicare program, which is exacerbated by heavy reliance on electronic payments in compensating providers. Disinterest on the part of law enforcement officials reflects a belief that costs appear to outweigh the benefits of investigation and prosecution. Large scale fraud discussed in Sparrow suggests the scope of the possible in developed countries where significant resources are devoted to health care; there is heavy reliance on automated payment arrangements most of which are never checked by humans; and inadequate controls are in place to prevent fraud and abuse. Similar types of fraud exist 
in some middle income countries, but there are far less sophisticated means employed with ample benefit in developing countries.

Governance indicators are built on perceptions of in-country and outside observers, and their application has emphasized cross-country comparisons. On the first point, perceptions are powerful factors in shaping behavior. If investors perceive corruption or patients perceive poor quality, it discourages private investment or health demand, respectively. But perceptions are only part of what is of interest in assessing governance issues in health

Less corrupt and politically stable countries the more attractive they are for private investors and donors (Kaufmann, Kraay and Mastruzzi, 2005). Good governance has been shown to correlate with property rights and civil liberties, and greater foreign investment (Hellman et al., 2000), and to "grease" the wheels of government (Kaufmann and Wei, 1999). Aid effectiveness also rises in countries with good governance. These clearly have relevance to health care.

Capturing the effectiveness of public health care services, the extent of corruption and the degree of accountability pose serious challenges, which contribute to the lagging effort to address governance in the sector. Using national level indicators such as access to health services provides limited guidance on how well the sector is performing. At the same time, performance indicators are scarce, and difficult to aggregate where they exist. The heterogeneous nature of health care and the large number of sui generis events; the highly variable and unpredictable nature of health care demand; the multiple actors involved in ensuring effective service delivery; and, the limited choice of instruments for monitoring all contribute to the challenge of defining and measuring governance in the health sector.

\section{Correlates of Poor Governance and Public Health Care across Countries}

The evidence on the link between institutions and health has largely relied on analyzing the cross-country relationships between corruption and health outcome measures. With evidence for 89 countries for 1985 and 1997 Gupta, Davoodi and Tiongson (2000) show corruption indicators (using Kaufman, Kraay and Zoido-Lobatón, 1999) negatively associated with child and infant mortality, the likelihood of an attended birth, immunization coverage and low-birthweight. The correlation of corruption in explaining the same health outcomes is reduced once factors such as mother's education, public health and education spending and urbanization are controlled for, but remains significant.

In measuring the impact of corruption on the effectiveness of health spending Rajkumar and Swaroop (2002) analyze data for 1990 and 1997 controlling for GDP per capita, female educational attainment, ethno-linguistic fractionalization, urbanization among other factors, and find that the effectiveness of public health spending in reducing child mortality hinges on the integrity rating (1-5 range based on level of perceived corruption), with higher integrity associated with reduced mortality. Poor governance 
may help to explain the inconclusive findings of Filmer and Pritchett (1999) on the lack of association between public health expenditures and infant and child mortality.

Wagstaff and Claeson (2005) extend these analyses further and use more recent data. They find that spending reduces under 5 mortality, but only where governance, as measured by the World Bank's CPIA score (Country Policy and Institutional Assessment measure that is scored between 1-5 depending on performance, part of which regards corruption and governance), is sound (a CPIA above 3.25). This study specifically explores the implications of additional spending for reaching the MDGs, and concludes that more spending in medium and low CPIA countries would not be expected to reduce child mortality, and that per capita income growth offers a better investment if mortality declines are the objective.

Because child mortality rates are measured with substantial error, especially in the poorest countries, these results need to be taken with caution. The uncertainty of the direction of causality introduces further limitations in the interpretations of the results. Cross-country regressions are hard to interpret in any event, but as an aggregate assessment they provide general guidance on the relevance of corruption and other factors in affecting health outcomes in developing countries. The inability of country level analysis to elucidate specific country problems leads to the subsequent section that addresses these issues, complementing this introductory look at the correlates of health outcomes.

Figure 1 demonstrates the relationship between governance indices and measures of health performance and outcomes. Measles immunization coverage provides a robust measure of public service performance as it reflects government's ability to perform a critical and basic health service. Measles immunization by itself is particularly important since when administered in infancy it sharply reduces all causes of mortality in childhood (Koenig et al., 1991; Aaby 1995). It is also easily measured. Child mortality is a standard variable for measuring health outcomes, is influenced by a wide range of factors beyond the quality and extent of health care services, but has the advantage that it is available for a large number of countries.

The six panels in Figure 1 show the scatter plots for both indicators and each of the three components of the KKM governance index: government effectiveness, control of corruption, and voice and accountability. Of the three measures, and compared to the aggregate governance indicator (not shown), government effectiveness best correlates with poor outcomes and performance in health care based on the smaller variation conveyed in the adjust $\mathrm{R}^{2}$. Voice has the least explanatory power and it is especially limited for immunization coverage. The panel on voice and accountability suggests why. The highly variable relationship especially among the countries with the lowest governance scores makes any effort to explain variation unconvincing. In higher performing countries more convergence occurs for government effectiveness and control of corruption but much less so for voice. Immunization programs are typically the

\footnotetext{
${ }^{1}$ When all three governance measures are jointly regressed on infant mortality and percent measles immunization, only government commitment and is significant and consistently shows the expected sign.
} 
responsibility of central governments because it is a preventive measure for which demand tends to be low among all but the most educated. ${ }^{2}$ The dispersion in the voice and accountability panel is consistent with that fact.

Figure 1. Relationship between corruption indices and health outcomes
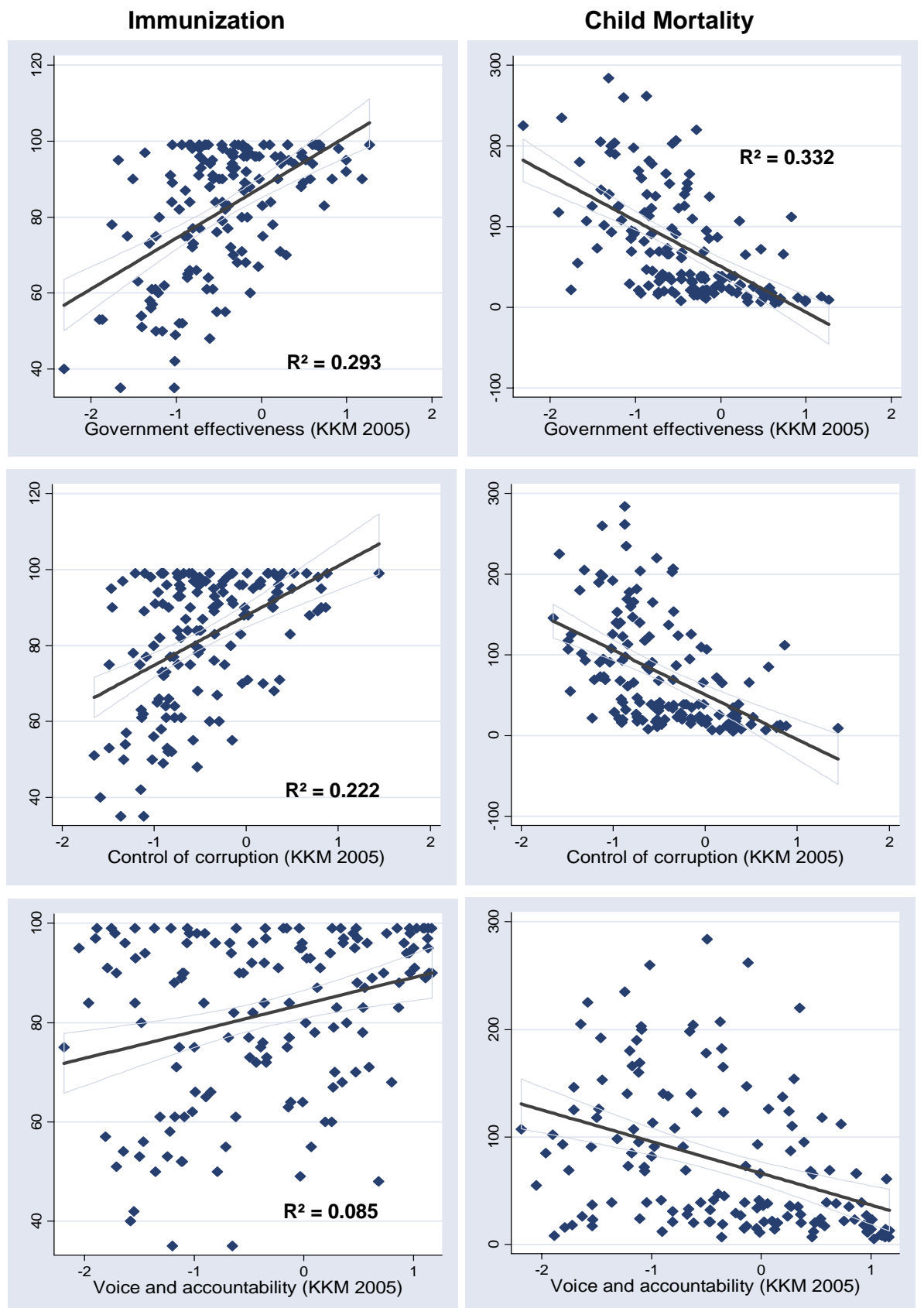

\footnotetext{
${ }^{2}$ Low demand for immunization occurs in developed countries as well, which accounts for the legal requirement in the US that children must be immunized before they enter day care or school. In the rest of the OECD governments take responsibility for ensuring immunization coverage.
} 
Table 1 provides OLS results showing the strength of governance measures on measles immunization coverage controlling for other relevant factors. Of the various governance indices, government effectiveness explains more of the differences in measles immunization and has a slightly stronger effect than the overall corruption index, which would be expected since immunization is a relatively simple technology and requires basic government capacity to do it well. Government effectiveness is consistent in its effect on immunization coverage. Controlling corruption (not shown) is significant but less robust than the other two measures, and voice has no effect at all on the percent of

\begin{tabular}{|c|c|c|c|c|c|}
\hline & (1) & $(2)$ & (3) & (4) & (5) \\
\hline \multirow{2}{*}{ Log of GDP per capita, PPP (const 2000 int'l \$) } & 2.351 & 0.808 & 0.487 & -0.136 & -1.378 \\
\hline & $(3.489)$ & $(3.561)$ & $(2.451)$ & $(2.609)$ & $(4.212)$ \\
\hline \multirow[t]{2}{*}{ Aggregate governance } & & 6.152 & & 5.201 & \\
\hline & & $(3.124)^{\star}$ & & $(2.442)^{\star \star}$ & \\
\hline \multirow[t]{2}{*}{ Government effectiveness } & 7.026 & & 6.812 & & 8.221 \\
\hline & $(3.218)^{\star \star}$ & & $(2.345)^{\star \star \star}$ & & $(3.607)^{\star \star}$ \\
\hline \multirow[t]{2}{*}{ Average years of schooling of adults, female } & 1.888 & 1.763 & & & 2.337 \\
\hline & $(0.981)^{\star}$ & $(1.008)^{\star}$ & & & $(1.071)^{\star \star}$ \\
\hline \multirow[t]{2}{*}{ Primary completion rate, female } & & & 0.293 & 0.309 & \\
\hline & & & $(0.067)^{\star \star \star}$ & $(0.073)^{\star \star \star}$ & \\
\hline \multirow[t]{2}{*}{ Ethnolinguistic and religious fractionalization } & & -6.021 & & -4.059 & -6.671 \\
\hline & & $(2.271)^{\star \star}$ & & $(2.263)^{*}$ & $(2.284)^{\star \star \star}$ \\
\hline \multirow[t]{2}{*}{ Road density } & & & & & -0.037 \\
\hline & & & & & $(0.015)^{\star \star}$ \\
\hline \multirow[t]{2}{*}{ Constant } & 56.180 & 77.120 & 57.689 & 66.128 & 94.809 \\
\hline & $(25.664)^{\star \star}$ & $(27.959)^{\star \star \star}$ & $(17.318)^{\star \star \star}$ & $(19.704)^{\star \star \star}$ & $(33.118)^{\star \star \star}$ \\
\hline Observations & 71 & 68 & 119 & 112 & 68 \\
\hline R-squared & 0.434 & 0.473 & 0.444 & 0.470 & 0.497 \\
\hline
\end{tabular}

Robust standard errors in parentheses

Sources: Kaufmann, Kraay and Mastruzzi (2005); Barro and Lee (2000); Alesina, et. al. (2003); World Bank World Development Indicators 2005; World Bank EdStats.

* significant at $10 \%$; ** significant at $5 \%$; *** significant at $1 \%$

children immunized. Road density would also be expected to impede immunization coverage, which it does, and it is significant. GDP per capita strongly affects immunizations, but not when other controls are added. Reaching children appears to be more of an impediment due to dispersed population or inadequate infrastructure. Per capita income may not be as important to increasing immunization given the generosity of donor funds, particularly for vertical programs like immunizations. The variable for women's education, a key input in whether children get immunized, is best captured by average years of schooling for females over age 15. However, the sample size declines by 40 countries when this variable is used, so the completion rate of females, the proportion of girls who are currently finishing school, is used as a proxy because girls' 
current achievements are a reflection of their mothers' support for education and their ability to make household decisions about their children's education .

Table 2 shows the OLS results for child mortality. The $\mathrm{R}^{2} \mathrm{~s}$ are almost 50 percent higher than those for measles immunization coverage, with income per capita and ethnolinguistic fractionalization explaining most of the variation. Average years of female schooling doesn't have an effect, although girls' completion rates do. Average years of female education becomes significant, however, when ethno-linguistic fragmentation is left out, suggesting either some substitution between these factors, or when the loss for so many observations affects the relationship. Governance is not significant, but it matters when the education variable is female education rather than completion. Road density and urbanization (not shown) have no effect, and that pattern persists with other models. The established inverse relationship between income and child mortality makes these results unsurprising, but the lack of importance of female education is odd given the strength of the relationship in country level studies. These results provide the point of departure for a more narrow focus on both the country level issues and the factors that directly influence health care delivery.

Table 2. OLS results for under-5 mortality rate

\begin{tabular}{|c|c|c|c|c|c|}
\hline & (1) & $(2)$ & (3) & (4) & $(5)$ \\
\hline \multirow[t]{2}{*}{ Log of GDP per capita, PPP (const 2000 int'I \$) } & -66.447 & -55.263 & -29.148 & -24.932 & -55.649 \\
\hline & $(7.853)^{\star \star \star}$ & $(9.847)^{\star \star \star}$ & $(8.403)^{\star \star \star}$ & $(8.390)^{\star \star \star}$ & $(9.856)^{\star \star \star}$ \\
\hline \multirow[t]{2}{*}{ Aggregate Governance } & 18.747 & 16.828 & & -3.069 & 18.644 \\
\hline & $(9.167)^{\star \star}$ & $(9.426)^{\star}$ & & (7.588) & $(9.866)^{\star}$ \\
\hline \multirow[t]{2}{*}{ Government Effectiveness } & & & -4.773 & & \\
\hline & & & $(8.576)$ & & \\
\hline \multirow[t]{2}{*}{ Average years of schooling of adults, female } & -3.819 & -3.893 & & & -3.563 \\
\hline & $(2.483)$ & $(2.551)$ & & & $(2.504)$ \\
\hline \multirow[t]{2}{*}{ Primary completion rate, female } & & & -1.261 & -1.197 & \\
\hline & & & $(0.194)^{\star \star \star}$ & $(0.213)^{\star \star \star}$ & \\
\hline \multirow[t]{2}{*}{ Ethnolinguistic and religious fractionalization } & & 19.222 & & 20.169 & 18.934 \\
\hline & & $(8.220)^{\star \star}$ & & $(5.525)^{\star \star \star}$ & $(8.155)^{\star \star}$ \\
\hline \multirow[t]{2}{*}{ Road density } & & & & & -0.054 \\
\hline & & & & & $(0.073)$ \\
\hline \multirow[t]{2}{*}{ Constant } & 639.747 & 521.888 & 408.635 & 342.705 & 526.372 \\
\hline & $(60.938)^{\star \star \star}$ & $(85.021)^{\star \star \star}$ & $(60.448)^{\star \star \star}$ & $(62.343)^{\star \star \star}$ & $(85.128)^{\star \star \star}$ \\
\hline Observations & 71 & 68 & 119 & 112 & 68 \\
\hline R-squared & 0.748 & 0.764 & 0.745 & 0.769 & 0.766 \\
\hline \multicolumn{6}{|l|}{ Robust standard errors in parentheses } \\
\hline \multicolumn{6}{|c|}{$\begin{array}{l}\text { Sources: Kaufmann, Kraay and Mastruzzi (2005); Barro and Lee (2000); Alesina, et. al. (2003); World Bank } \\
\text { World Development Indicators 2005; World Bank EdStats. }\end{array}$} \\
\hline \multicolumn{6}{|c|}{${ }^{\star}$ significant at $10 \% ;{ }^{\star \star}$ significant at $5 \%$; ${ }^{\star \star \star}$ significant at $1 \%$} \\
\hline
\end{tabular}

The next section summarizes accumulated evidence on specific components of governance and corruption, including: perceptions of corruption and performance; management challenges in public systems; staff absenteeism; under-the-table or informal payments for health services; corrupt practices including misuse of public funds, 
irregularities in contracting and purchasing supplies, petty theft and the selling of positions and promotions. As symptoms of poor performance, they provide an empirical base for exploring priority areas for attention and intervention.

\section{Government Effectiveness, Corruption and Accountability in Health Care Delivery}

Separating three components of governance - government effectiveness, corruption and accountability -- allows targeting policies to specific shortcomings. However, the information base is thin and the elements so intertwined that a separate analysis of each yields little benefit. For example, evidence from provider and other surveys in Mozambique, Nigeria and Uganda suggest that the level of mismanagement, vague and poorly understood performance expectations and the singular lack of accountability to anyone or any institution makes haphazard and corrupt practices difficult to identify, separate or control ( Lindelow, Ward and Zorzi, 2004; Lindelow, Reinikka and Svensson, 2003; Das Gupta, Gauri and Khemani, 2003; McPake et. al., 1999).

There is a fine line between inefficiency and corruption in many instances. Is poor service a function of corruption or simply mismanagement? Better accountability can address both, so should the approach be combined or separated? In the interests of clarity, this section will discuss governance, corruption and accountability jointly reviewing the evidence and offering an interpretation of those findings as they relate to each of these criteria.

This discussion begins with an assessment of perceptions of corruption in select countries to provide that context. It then addresses the production function elements in reviewing country level evidence. The analysis tracks productivity of labor, and capital inputs: drugs, supplies and national transfers, complementing these with a brief assessment of management, a central component for correcting many of the problems identified.

\section{A. Perceptions of Corruption in Public Health Care Systems}

While not strictly part of the production function, perceptions about corruption reflect how stakeholders view health systems and their effectiveness in producing acceptable health outcomes. Perceptions provide the basis for assessing governance at a national level, and similar estimates have been collected for the health sector in a subset of countries. Extensive, cross-country surveys of public officials, the business community and the general public gauge perceptions of corruption in public service. At a sectoral level a number of recent perception surveys of medical personnel in Latin American public hospitals provide a sense of the kinds and frequency of corruption in facilities as well as the likely perpetrators by profession (Di Tella and Savedoff, 2001). Both types of surveys indicate corrupt practices, which by their nature are not typically visible. Perceptions may be the only alternative in instances where hard data are either unobtainable or unreliable, and corruption in general does not lend itself to straightforward data collection. 
Figure 2 summarizes the perceptions of the general population toward corruption in health in a selection of countries for which data are available. Data come from various sources all largely based on perceptions and they are not strictly comparable though they suggest general levels of corruption in the included countries. Coverage is uneven with a bias towards the countries of Eastern Europe and Central Asia (ECA) and South Asia where data are more plentiful. Of those at or above 60 percent of the population perceiving corruption in the health sector half are ECA countries, results partly due to the disproportionate number of ECA countries.

In corruption surveys interviewing public officials, business executives and the general public in 23 countries, health ranked first as the most corrupt sector in Moldova, Slovakia and Tajikistan, second in Bangladesh, India and Sri Lanka, and in the top four in Kazakhstan, Kyrgyz Republic, Madagascar and Morocco. For the most part these countries also ranked highly on the percent of the population perceiving high levels of corruption in health - going as high as 95\% in Pakistan, 92\% in Sri Lanka, 85\% in Tajikistan, $82 \%$ in Moldova and $80 \%$ in Morocco. ${ }^{3}$ Expectations on paying for public care correspond to the perceptions of corruption, which in turn are closely related to the need for informal payments, as will be discussed below.

A related 2001 perceptions survey conducted by USAID on corruption among public officials in Bosnia and Herzegovina, Bulgaria, Macedonia, Romania, Croatia, and Montenegro showed that $45-55 \%$ of respondents felt that corruption among doctors was widespread. Albania and Serbia showed much higher levels -- 61-71\% range. Albania's perception score for doctors was an outlier relative to its score for other public officials, but Serbia exhibited levels above those of other countries for most categories of officials, suggesting a relatively more corrupt environment (Vitosha/USAID, 2002).

Business Environment and Enterprise Performance Surveys of administrative corruption in ECA capture business managers' perceptions of health service quality. Across 20 countries only Slovenia and Czech Republic had positive assessments from 60\% or more of respondents, indicating management and governance problems in the other 18 systems (Ryterman, Hellman, Jones et al., 2000).

In Bolivia a local survey of patients considered the Health Ministry and public hospitals less corrupt than customs or police, but ranked corruption 2.7 on a scale of $1-4$, noting the nepotism, clientelism and higher charges for the unconnected as some key indicators of corruption (Gatti, Gray-Molina and Klugman, 2004), evidence that has been corroborated in other studies as discussed below. Surveys from South Asia suggest similar perceptions of the health sector (Thampi, 2002).

\footnotetext{
${ }^{3}$ It is counter-intuitive that only $15 \%$ of the Indian public and $9 \%$ of the Kazak public perceive corruption in the health sector when they ranked it so highly on perceptions of corruption in the sector. This bears further investigation.
} 
Figure 2. Percent Perceiving Corruption in the Health Sector

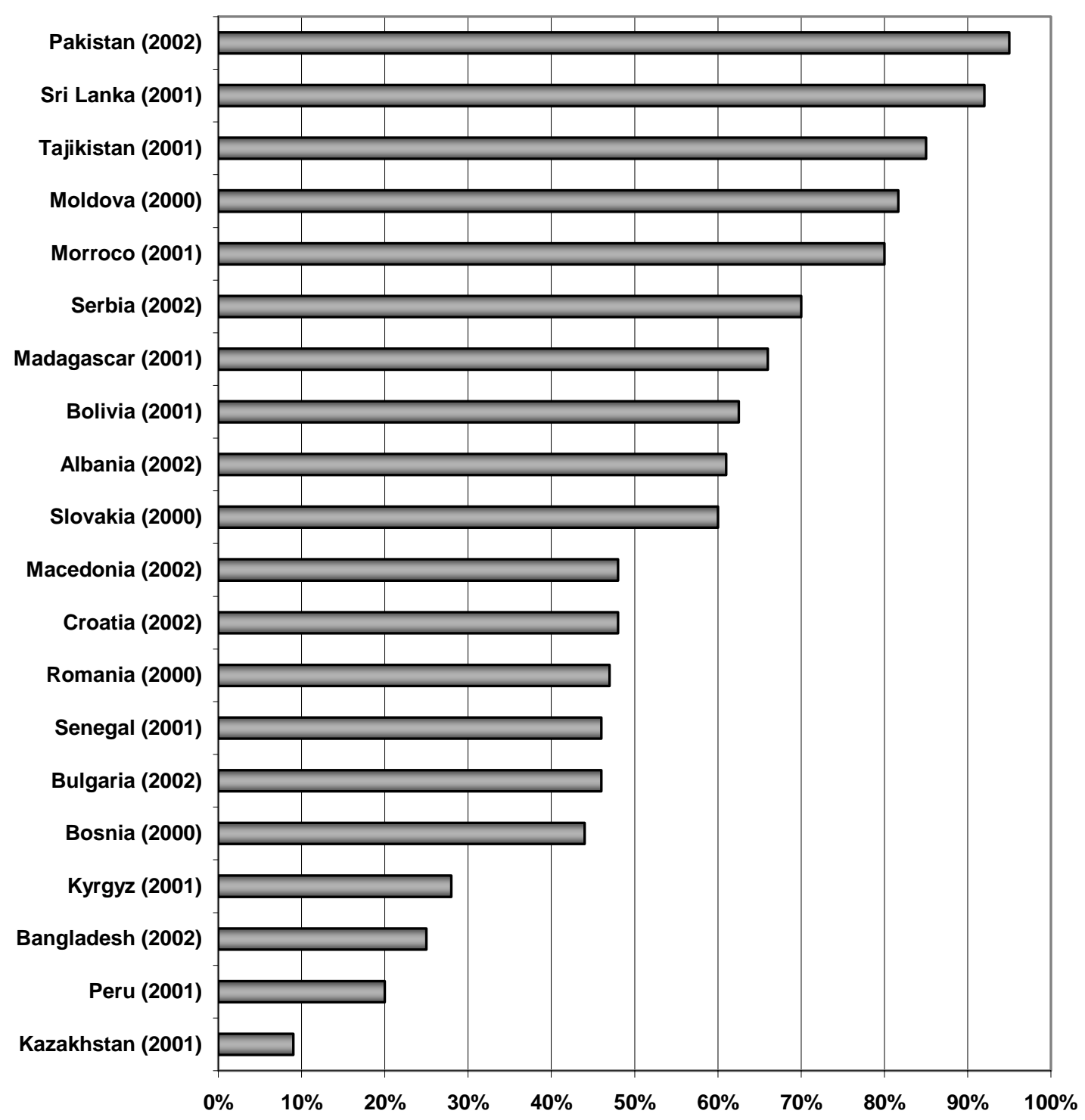

Source: Appendix I 
A comparison of corruption perceptions among households in the Philippines and Uganda found 34 and 71 percent, respectively, reported that corruption is common or very common in government generally. And among local officials, 25 percent in the Philippines and 61 percent in Uganda acknowledged some kind of corruption in public services within the municipalities (Azfar and Gurgur, 2001).

Explanations from the surveyed on why corruption is so evident in the health sector emphasize the lack of accountability and transparency in health care operations, and in some the "power of monopoly" where other public or private alternatives simply do not exist (Thampi, 2002; McPake et. al 1999; Lewis, 2000, 2002; Narayan, 2000). While not definitive, perceptions highlight where abuses are assumed and widespread and they have become reliable indicators of corruption. Only a few countries have sector specific data on perceptions. Greater efforts to track such information can guide both policymakers and donors providing a benchmark for individual countries.

\section{B. Staffing Health Care Delivery}

Staffing is arguably the single most important element of health care delivery as little can be achieved without it. Training of the staff, their competencies and ability to function all determine whether labor can drive the expected results. Training typically is adequate if not well beyond that needed in the lowest income countries, especially for physicians. Availability of the full range of competencies, however, often lags with particular inattention to management needs, and lower paid staff with minimal skills can proliferate.

Among the most serious issues in developing countries is the high rate of absenteeism, which undermines service delivery and leads to closed public clinics that compromise the equity and health objectives of publicly financed health care. Two other commonly observed constraints include low productivity of public medical staff, and the outright corruption that underlies the buying and selling of official positions. Capturing low productivity and poor service poses greater difficulties; absenteeism already reflects reduced output, and underperformance. Patient satisfaction provides an additional window into adequacy of staff services.

Absenteeism. Absenteeism poses a chronic, but often unmeasured, problem in publicly financed health care, and can severely limit patient access to services (McPake et. al., 1999; Lewis, Eskeland and Traa-Valarezo, 2004; Narayan, 2000), reduce quality (McPake et. al., 1999; Lewis, La Forgia and Sulvetta, 1996), and suggest corruption (DiTella and Savedoff, 2001).

Absenteeism occurs for various reasons, many of them legitimate or necessary. For example, rural health workers often need to travel to larger towns to receive their paycheck, fetch supplies or drugs or are delayed by poor infrastructure or weather. All lead to absences but are necessitated by inadequate management or other shortcoming of the country context. On the other hand, some staff have other commitments or preferences and don't show up. In effect they receive a salary but provide minimal if any services. This is effectively theft, a form of "public office for private gain." 
Capturing the extent of absenteeism among public service staff is made difficult by the lack of or incomplete nature of staff attendance records. Various alternatives have been applied to examine the issue including perceptions of other providers (DiTella and Savedoff, 2001).

Figure 3 compares absenteeism rates for studies that report such data, and measurements vary, as do level of provider, number of observations within each provider unit and location. Chaudhury, et al., (2004) use a single surprise visit to a nationally representative sample of rural clinics in 5 countries; Banerjee, Deaton and Duflo (2004) tracked absences in 143 government facilities in Udaipar district in Rajasthan, India based on weekly visits over 18 months; Lewis, LaForgia and Sulvetta (1996) used time and motion studies during a two weeks period to track health provider attendance in a single hospital in Santo Domingo, Dominican Republic; and, McPake et al. (1999) directly observed clinics in 10 rural districts in Uganda over the course of one week. Thus the reported absences are captured using different time frames, samples and providers.

Absenteeism rates, measured in these particular studies, range from a low in Mozambique and Papua New Guinea of 19 percent to over 60 percent among physicians in a Dominican hospital, in rural Bangladesh and Uganda, but cluster around 35-40 percent for the others. These results suggest a serious gap in health service coverage due to absent staff, levels considerably above those from similar studies in the same countries for teachers (Chaudhury et al., 2004). As in Figure 2, these results rely on different types of surveys over varying time periods and for a variety of services. What is noteworthy are the range of methods, the lack of consistency and the need to establish acceptable and regular means for tracking staff absenteeism. Otherwise it will remain an ad hoc

Figure 3. Absence Rates Among Health Workers in Selected Countries

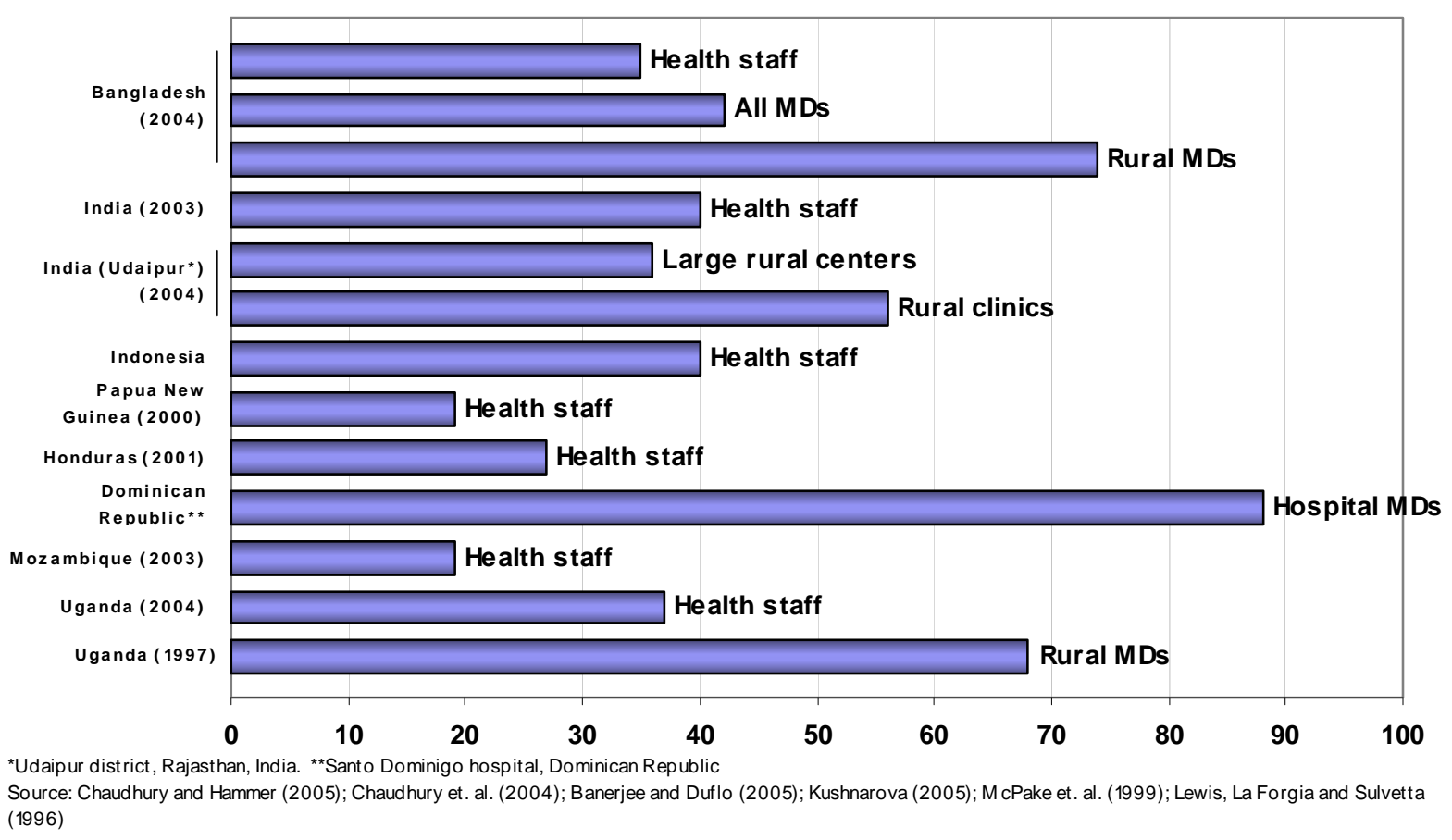


approach.

Lewis, La Forgia and Sulvetta's (1992; 1996) time and motion studies in inpatient, outpatient, surgery and emergency found that not only did physicians only provide $12 \%$ of contracted time, nurses provided virtually no care outside of inpatient services, and staff physicians, residents and interns provided only 7, 4, and 8 percent of their contracted time, respectively. As found in Uganda (see below), absenteeism was lowest during the early morning hours and in the outpatient department. In the DR, surgery was only conducted before noon during the availability of surgeons, leaving the facility idle for the remainder of the 24 hour day. Interns, residents and auxiliary nurses received virtually no supervision from staff physicians and nurses. The resulting services were under-staffed and reliant on untrained providers with virtually no supervision. The abuses translated into high costs for the public sector with little output, and undermined the quality of health care across the board by relying on ill-trained providers for care and under investing in the quality of future providers.

Residents and auxiliary nurses received virtually no supervision from staff physicians and nurses. The resulting services were under-staffed and reliant on untrained providers with virtually no supervision. The abuses translated into high costs for the public sector with little output, and undermined the quality of health care across the board by relying on illtrained providers for care and under investing in the quality of future providers.

McPake et al., (1999) recorded attendance and clinic openings. Clinics only remained open for 2-3 hours in the morning with partial coverage by health staff, often on a rotating basis. Doctors, medical assistance, midwives and nurses were available for an average of 12.9 hours per week while nursing aides, dressers and pharmacy orderlies worked an average of 18.5 hours. The latter group of lower level health workers provided 71 percent of total available hours of staff at the clinics compromising quality as well as coverage. These estimates ignore the "ghost" workers who never attend the facility, suggesting that the average attendance of contracted staff is even lower than the estimates.

Chaudhury and Hammer's (2004) study of absenteeism in rural health clinics in Bangladesh recorded availability of doctors and paramedics of filled positions. ${ }^{4}$ On average $35 \%$ of staff and $42 \%$ of physicians were absent across the 60 clinics visited. In eamining clinics by location, absenteeism in the most rural areas was $74 \%$ for doctors. Subsequent multivariate analysis showed that living outside the service village, being female and poor road access increased the likelihood of absenteeism among physicians. Absenteeism was associated with clinics in disrepair as well as with lower patient demand, suggesting that absenteeism compromises quality and quantity of services.

\footnotetext{
${ }^{4}$ They found that $26 \%$ of positions and $41 \%$ of physicians slots were vacant, suggesting that the total available stock was already below what was demographically required and budgeted.
} 
The studies in Uganda and Rajasthan, India added a search for absent primary health care workers. Over the course of 18 months Indian nurses were only to be found in villages served by the subcenter 12 percent of the time, and all were assigned to staff the clinic on a regular basis. The pattern of absences, and therefore closure of facilities, followed no pattern meaning that patients' likelihood of finding a provider was unpredictable (Banerjee, Deaton and Duflo, 2004). Health workers were often found at home in Uganda, although some employees simply never attended the facility and were designated as "ghost" workers (McPake et al., 1999). The costs represented by absent staff are not insignificant given the higher levels absenteeism, which are consistently higher than those found in education.

Absenteeism based on perceptions provide some orders of magnitude of nonattendance, but may be less objective than the recorded observations or surprise visits discussed above. Nonetheless they are instructive.

Absenteeism is considered the most serious corruption problem in Colombia, but perception of absenteeism varies across the six Latin American countries for which qualitative survey data are available (Giedion, Morales and Acosta, 2001). Surveys of hospital nurses' perceptions of the frequency of chronic absenteeism among doctors reported rates of 98\% in Costa Rica, 30\% in Nicaragua, 38\% in Colombia (Giedion, Morales and Acosta, 2001) and between 24-31\% across public and social security hospitals in Argentina (Schargrodsky, Mera and Weinschelbaum, 2001). In Peru estimates of hours absent from work ranged from 12 to 36 hours (Alcázar and Andrade, 2001) across the sampled hospitals.

Shaving off hours is more commonly reported than absent days in all the Latin American country surveys. Late arrival and early departure only represented 2- 23 percent of all absences in a four country study (Uganda, Bangladesh, India and Indonesia) of medical personnel based on surprise visits (Chaudhury, et al, 2004). The Colombia case study above estimated that the cost of the lost time in the public hospitals of Bogotá was equivalent to over US\$1 million per year.

Focus groups in Ethiopia among health workers revealed common understaffing due to late arrivals, long breaks and a general disregard for the necessity of staffing clinics. Absences are frequently motivated by responsibilities at second jobs. Lack of management and manager's reluctance to confront physicians inspires lower level workers to behave accordingly, leading to high absenteeism and low productivity at all levels. (Lindelow, Serneels and Lemma, 2003)

Where absenteeism is endemic, as was the case in Uganda, Rajasthan India and the Dominican Republic, such explanations are far less compelling. One factor shared by all of the examples above is that absent health workers face almost no consequences. There is no accountability for public servants. Without accountability, abuses are more likely to proliferate and eventually undermine the health care system.

Multivariate evidence for education provides some important insights. The correlates of teacher absences in five countries produced mixed findings but in at least three countries infrastructure quality mattered consistently, and, in some, Ministry of Education 
inspections were also associated with lower absenteeism. Education of mothers, community oversight, location of schools and the training of teachers, had perverse or insignificant effects on absenteeism. To the extent that inspectors were indeed a tool of accountability, they had some effect in Ecuador, India and Indonesia but no effect at all in Peru and Uganda. The consequences of high absenteeism were not discussed nor were any other forms of accountability (Chaudhury et al, 2004).

Absenteeism is symptomatic of an unaccountable and ineffective government, and leads to contempt for government, its policies and practices, and compromises both access to and quality of health care services. Unproductive or absent workers who do not receive any punishment for substandard performance and whose promotion and pay remain the same as those with better performance, undermine morale and reduce output, which in turn leads to a spiral of overall poor performance. Accountability is meaningless or doesn't exist without sanctions, and institutions suffer accordingly.

Purchasing Public Positions. The insidious practices of selling public positions and requiring bribes for promotion fundamentally undermine good performance and builds a corruption spiral since the newly hired and promoted must find the resources to ensure their continued employment and advancement. The practice has been documented for much of Eastern Europe and Central Asia where the breakdown of government led to the commercialization of public positions (Kaufman, Pradhan and Ryterman, 1988).

Outright purchase of public employment through bribes is often anecdotally accepted, but some recent work has tried to quantify it. Evidence from surveys of public officials in Latvia, Armenia and Georgia showed that the "cost" of public positions was well known among public officials and the general public. Interestingly the higher cost jobs were in the most corrupt enclaves of government (Kaufman, Pradhan and Ryterman, 1988).

In Bosnia and Herzegovina bribes were particularly common in the health sector with surveys of officials and citizens reporting that 75 percent thought bribes were required for obtaining positions and for promotion (World Bank, 2001e). In Ghana 25\% of jobs were allegedly bought in government hospitals. In Uganda 20 percent of municipal officials acknowledged that the practice occurred in the health sector, and in the Philippines 3 percent noted it (Azfar, Kahkonen and Meagher, 2001).

In focus groups in Ethiopia health officials complained about unfair hiring practices, nepotism and preferential treatment to well connected individuals. Similarly in the Dominican Republic “patronage propelled personnel rolls” leading to one of the highest rates of health personnel to population in the region. Promotions routinely rely on recommendations from politicians, and military authorities that lead to a mismatch between skills and needs (La Forgia et al, 2004). An earlier study found that most care was already provided by under-trained medical students operating on patients without supervision (Lewis, La Forgia and Sulvetta, 1992).

Staff accountability for misconduct is rare. Its absence in accountability is noted for the Dominican Republic (La Forgia et al, 2004), although Cohen (2002) reports that in Costa Rica 27 percent of users know of a case where sanctions were imposed or a public 
employee was terminated for corruption or theft. So there are some countries where at least egregious misconduct is disciplined.

Collusion among public officials has also been identified as perpetuating corruption. In Bosnia and Herzegovina (World Bank, 2001e) 35 percent of officials said health colleagues who refuse bribes face retribution, and similar views were expressed in focus group discussions among public health staff in Ethiopia.

\section{Supplies: Mismanagement and Corruption}

Availability of drugs and supplies complement health professionals and their absence reflect poor management or corruption.

Drug Management and Leakage. Virtually all qualitative studies that have probed this issue have emerged with the view that quality and drug availability are virtually synonymous, and lack of drugs has been repeatedly shown to discourage utilization of public facilities (World Bank, 2005a). A recent in depth assessment of the Costa Rican pharmaceutical system's registration, drug selection, procurement, distribution and service delivery revealed both great strengths and glaring weaknesses. The study used a combination of (i) interviews with public officials; (ii) industry interviews with local pharmacies and multinational companies; (iii) focus groups with health care professionals; and, (iv) exit surveys for a representative sample of patients.

Clear publicly available procedures, pharmaceutical lists and criteria; reliance on defined, generic drugs; and distribution audits were deemed excellent. The greatest weaknesses were in procurement, specifically in the lack of performance monitoring, quality monitoring, audits and uncontrolled political interference; and in distribution where inventory management, security and information systems were found particularly deficient. Alleged abuses in service delivery by both health professionals and patients were attributed to lack of controls in prescribing and supplying drugs to patients.

Surprisingly, half of exit survey respondents had not received a prescribed drug due to non-availability, an important indicator of ineffectiveness (Cohen, 2002). Costa Rica's strong record in health care delivery and its relatively higher income, greater health spending and education levels among developing countries suggests the difficulty and challenges inherent in managing health systems and drugs in particular.

Drugs tend to be a commonly "leaked” product given that it can fetch a higher price in the private market. In Ethiopia users and providers explained in focus groups the rampant stealing of public sector drugs, their resale in the private market and the common dealings in contraband medicines. They acknowledge the lack of drugs in the public sector and the ready availability of those drugs in private pharmacies and clinics. A health officer in Addis Ababa noted that "most health workers are involved in such things [theft]" attributing this to "outside temptations" and low pay of public servants (Lindelow, Serneels and Lemma, 2003). Surveys in Nigeria found that 28 PHC facilities had not received drugs from the federal government in two years, and a World Bank 
study reported that les than half the facilities in Lagos and Kogi states had government supplied drug stock in 2001 (Adeniyi, 2001). In Costa Rica 32 percent of users indicated that they had prior knowledge of theft in government pharmacies (Cohen, 2002), and in a hospital study in the Dominican Republic comparing patient prescriptions and records of administered drugs a significant proportion of drugs went missing.

The average leakage rate for drugs in Uganda was estimated at 73\%, ranging from 40 to $94 \%$ across 10 public facilities. High demand drugs, such as those to treat malaria, were the least available to patients because health workers and the Health Unit Management Committee members, the entities meant to provide local oversight, expropriated them (McPake et al, 1999). A later facility exit survey in Uganda shows much higher drug availability and distribution, however (Lindelow, Reinikka and Svensson, 2003). In China various studies indicate that on average about 30 percent of public drug supplies are expired or counterfeit (Hsiao, 2005), suggesting poor logistics management, limited oversight and graft.

More insidious and difficult is drug mishandling from the importation of substandard medications, to the repackaging of drugs, substituting lower cost/quality medications, to the pilfering of drug supplies at points of service (e.g., clinics and hospitals). The health consequences of tampering can be serious, but rarely traced to the source of the problem due to ignorance, lack of regulation and enforcement.

In-kind Supplies from Patients. Interviews and focus groups from around the world reveal the common need to either bring or purchase basic supplies (e.g., bed sheets, bandages) or drugs (Narayan, 2000; Lewis, 2000, 2002) and in some instances equipment. The concentration of private health services adjacent to public hospitals and clinics in many countries attests to the chronic shortages of basic inputs and malfunctioning equipment. In Kyrgyz Republic in 2001 among hospitalized patients 98 percent brought food, 73 percent linens, 80 percent had family members purchase drugs and 76 percent supplied medical supplies (Falkingham, 2002). Similarly in Tajikistan in 199977 percent spent on food, 93 percent on medicines and 51 percent for medical supplies (Falkingham, 2004). Thus the health care system supplied little of the operating inputs in either country. Patients paid for 50 percent of drugs in the Dominican Republic hospital (Lewis, LaForgia and Sulvetta, 1996).

In Nigeria $25 \%$ of health facilities had about half of the minimum package of equipment, while $40 \%$ had less than a quarter of what was needed (World Bank, forthcoming). In Ethiopia two separate surveys revealed that only 21 percent of public hospitals had autoclaves (sterilizers) and 46 percent had functioning operating theaters, both serous shortcomings given the spreading AIDS epidemic and the high volume of patients (World Bank, 2005b). A study in Udaipur district in Rajasthan, India found patchy availability of basic equipment in health facilities with only a quarter having sterilizers. A third of sub-centers lacked a stethoscope, thermometer or scale (Banerjee and Duflo, 2005). 


\section{Corruption in the Supply Chain}

Graft and padding of billings form a commonly identified form of corruption in the public sector, and health care is no exception. The constant need for supplies to complement the skills and infrastructure investments of government offer an opportunity for petty theft.

Siphoning of public funds for private gain can occur in the transfer of funds from public treasuries to ministries of health, from the ministries to their provider units, and within the provider units themselves. All of these levels provide opportunity for theft. Misuse of funds often occurs in the process of tendering and payment, something all countries need to guard against through required procedures and regular audits. Having clearly articulated policies and procedures, adherence to policies and regulations, and consistent enforcement of rules discourage illegal behaviors.

In a 4 province survey across 80 municipalities in the Philippines corruption perceptions of households was negatively associated with providers' knowledge (of required immunizations), which in turn was strongly related to immunization coverage and disease incidence in the survey areas. Although significance is not highly robust in all cases, the analysis illuminates the negative relationship between corruption and performance at the local level (Azfar, Kahkonen and Meagher, 2001).

The contracting process for construction and the purchase of supplies offers a traditionally rich source of returns for corrupt officials and suppliers through kickbacks, over-invoicing or outright graft. A recent study of 7 Latin American countries provides insights on overpayment for supplies (DiTella and Savedoff, 2001).

In Argentina, Bolivia, Colombia and Venezuela overpayment for supplies in public hospitals points to corruption. Perceptions of staff, their assessment of the probabilities of getting caught and being punished, and examination of hospital records and comparing these with market prices suggest that irregularities are rife. Figure 4 shows the ratio of highest to lowest purchase price for four commonly stocked medical supplies - saline solution, cotton, dextrose and penicillin -- across hospitals in each of the four Latin American countries for which data exist. The poor procurement performance underlying the purchases were attributed to gross mismanagement or corruption (Di Tella and Savedoff, 2001).

In Colombia, it is estimated that about 11 percent of costs could have been saved if accepted public tendering rules had been followed (Giedion, Morales and Acosta, 2001). Results from surveys of physicians and nurses in Argentina (Schargrodsky, Mera and Weinschelbaum, 2001), Colombia (Giedion, Morales and Acosta, 2001) and Venezuela (Jaén and Paravisini, 2001) show that corruption within facilities leads to overpayment of suppliers, and that combined with the lack of punishment and the low probability of getting caught make it possible. In short, the lack of enforced rules, procedures and accountability effectively allows irregularities in purchasing practices. 
In Argentina a similar finding emerged. When the health system transparency policy was introduced the prices of procured supplies dropped sharply but rose again once the policy was no longer enforced (Schargrodsky, Mera and Weinschelbaum, 2001). In Colombia price variations were statistically significant across purchases of public hospitals, and particularly different where they ignored the price lists negotiated and endorsed by a local NGO under contract to the government (Giedion, Morales and Acosta, 2001).

Direct and specific evidence is harder to come by. However, in Ghana interviews with officials and the public suggest that $21 \%$ of procurements in government hospitals are corrupt, and $18 \%$ of the value of contracts is required in kickbacks to public officials (World Bank, 2000d). Petty theft in the aggregate can lead to significant losses, making it not so petty. Anecdotal evidence is abundant, but hard evidence elusive. Qualitative work has unearthed some strong perceptions and knowledge of petty theft providing a sense of its importance, and lending credence to allegations of theft.

Figure 4. Comparison of Purchase Price Difference for Selected Medical Supplies Across Public Hospitals in Four Latin American Countries

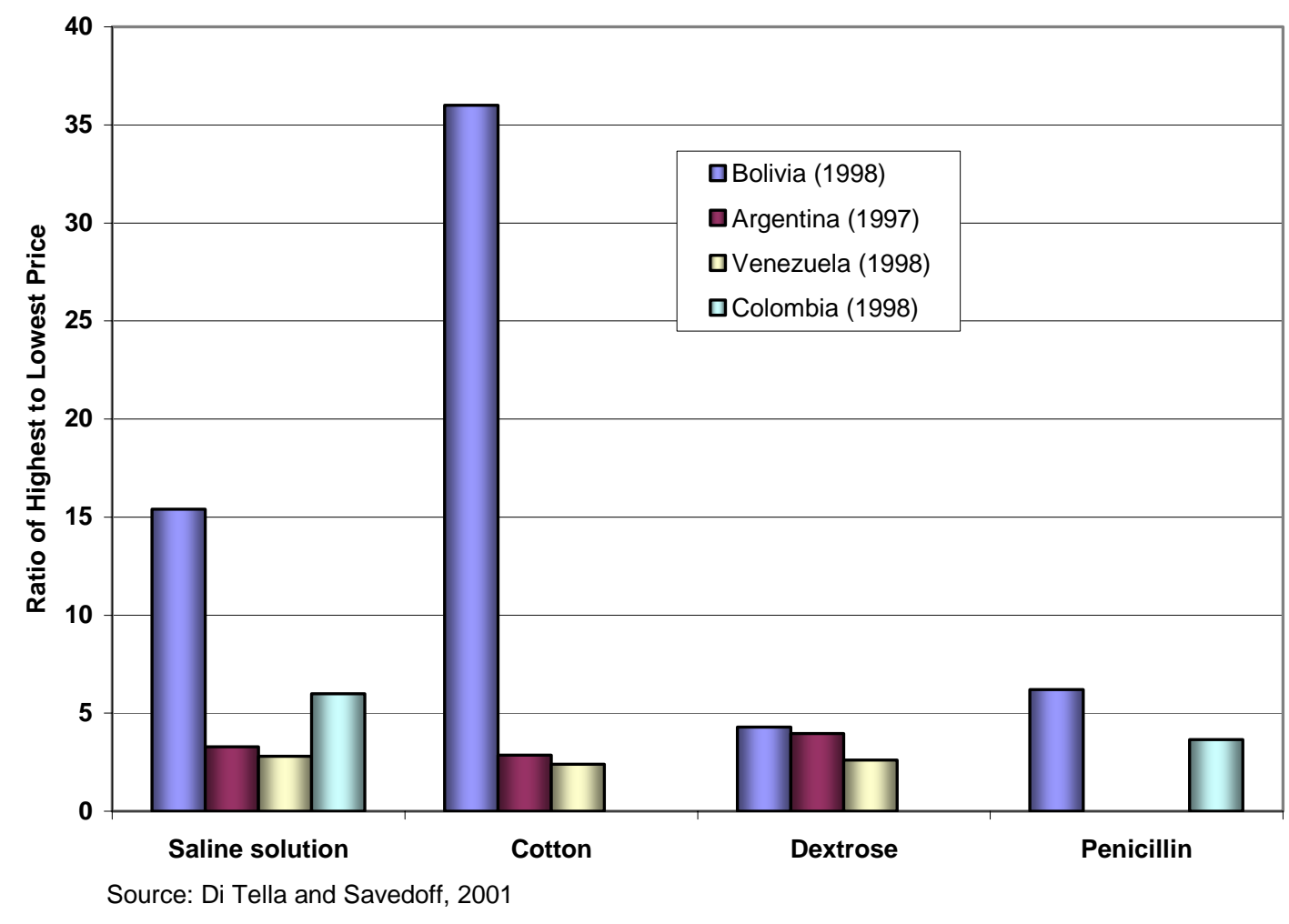

Petty theft was considered very common in Costa Rican hospitals where 83 percent of nurses reported thefts (Di Tella and Savedoff, 2001), and in Venezuela where roughly two-thirds of health personnel were aware of stolen materials, equipment or drugs (Jaén and Paravisini, 2001). In Peru, theft by both physicians and nurses was viewed as the 
most common form of corruption, with the highest estimated prevalence in Ministry of Health hospitals -- 22 percent, double that reported for Social Security hospitals (Alcázar and Andrade, 2001).

The lack of discipline and oversight makes it easy for corrupt officials to report higher costs for supplies, food and other goods and to pocket the difference. Even in developed countries, pharmaceuticals and supplies tend to be locked and closely inventoried to track supplies and drugs on a continuous basis because theft poses so much of a threat. Most public health systems in developing and transition countries lack the ability to limit access to drug supplies and the infrastructure to control access, although there are some exceptions. The absence of information systems for supplies and drugs, and an inability to sanction (or hold accountable) abusing staff makes control of theft particularly challenging.

\section{Flow of Funds}

Subsidized health care is meant to rely on public funding and minimally, if at all, on patients. In many places, bureaucratic problems, corruption and mismanagement lead to inadequate public funds at the point of service and the informal charging of patients compensates for inadequate salaries and gaps in discretionary budgets. At the same time informal charging may have serious equity implications undermining the objectives of subsidies.

Leakage of Public Funds. Whether public resources for staff and other inputs reach the front line -- the clinics and hospitals that deliver the services to the population - is critical to a functioning health system. The World Bank has pioneered efforts to measure the extent of leakage, that is, the amount of the line ministries' budgets that reaches the intended communities and the schools, clinics and hospitals funded through national transfers. These public expenditure tracking studies (PETS) simply follow the flow of funds through the labyrinth of government bureaucracy to determine if funds reach each of the designated levels.

First applied in education, PETS identified key problems of effective public management. In Uganda, 87 percent of funds never reached the schools (Dehn, Reinikka and Svensson, 2003). In Zambia it was 60 percent. Table 3 summarizes available evidence for the health sector in four countries: Ghana, Peru, Tanzania and Uganda where leakage is 70 percent or higher in all but Tanzania. High leakage means inadequate funding for nonsalary spending, which makes the job of service delivery exceedingly difficult and necessarily imposes on patients to finance "free" health care through financial or in-kind contributions. In Nigeria, Papua New Guinea, Rwanda, Senegal, there is evidence of leakage but neither the levels nor the sources of the problem have been determined. Leakages are a reflection of delays and bottlenecks in budget execution and supply management, poor record keeping and underutilization of audits, as well as incompetence and criminal acts. Incomplete and error riddled records complicate efforts to track financial flows, which is why so few countries have comparable data despite the number of country studies undertaken. 
Table 3: Leakage Rates for Health Care, Selected Countries

\begin{tabular}{|l|c|c|l|}
\hline COUNTRY & YEAR & $\begin{array}{c}\text { LEAKAGE } \\
\text { RATE }\end{array}$ & TYPE OF EXPENDITURE \\
\hline Ghana & 2000 & $80 \%$ & Non-salary budget \\
\hline Peru & 2001 & 71 & “Glass of Milk” Program \\
\hline Tanzania & 1999 & 40 & Non-salary budget \\
\hline Uganda & 2000 & 70 & Drugs and supplies \\
\hline
\end{tabular}

Source: Lindelow, Kushnarova, and Kaiser, 2005

In the case of education in Uganda, informing the public of expected school transfers and reporting receipt of funds to the community led to dramatic increases in non-salary budgets. Effectively the community monitored and pressured local officials to make sure that funds were applied as intended (Reinikka and Svensson, 2004).

Informal Payments. Informal payments can be defined as "payments to individual and institutional providers, in kind or in cash, that are made outside official payment channels or are purchases meant to be covered by the health care system. This encompasses 'envelope' payments to physicians and 'contributions' to hospitals as well as the value of medical supplies purchased by patients and drugs obtained from private pharmacies but intended to be part of government-financed health care services.” (Lewis, 2000, 2002). More specifically they are under-the-table payments to doctors, nurses and other medical staff for jumping the queue, receiving better or more care, obtaining drugs, or just simply for any care at all.

Informal payments create a parallel market for services within public health care systems, and, like the informal sector, informal payments are typically illegal and unreported. They can be considered a form of corruption, but may just be symptomatic of bad management. While only recently defined and discussed, what emerges from the data is, surprisingly, how widespread informal payments have become.

A major challenge is differentiating informal and gratitude payments given the official co-payment, bribes and gifts that patients pay. Where all fees have been banned any payment by households is clearly unofficial, but in many countries formal fees exist, blurring the dichotomy. It then becomes the level of payment, the nature of the transaction and its timing that become relevant for distinguishing the nature of the payment. For example, in Kyrgyz Republic in 200195 percent of those who paid for services did not receive a receipt while only 3 percent reported giving a gift to the health personnel and the time of service (Falkingham, 2002). A Bolivia study showed that perception of corruption was associated with the size of informal payment with a significant coefficient of .34 (Gatti, Gray-Molina and Klugman, 2004).

Ex post transactions are particularly problematic because post-service gratitude gestures are common and often expected. Where providers insist on direct pre-payment without 
involvement of official cash windows, refuse patient care without the fee, receive direct payments for specific tasks, or refuse basic services without a "tip" (e.g., such as moving patients from room to room, or giving injections) informality of payment is likely.

Figure 5 summarizes the frequency of informal payments to public health care workers among users of health services based on survey data from various sources. The frequency range is enormous from 3 percent in Peru to 96 percent in Pakistan. Regionally South Asia stands out for its heavy reliance on informal payments. East Asian experience is split between Thailand and Indonesia with low levels and the former Communist countries, with Cambodia at 55 percent and a dated estimate for Vietnam at 81 percent. The proportions for Latin America and Eastern Europe have a wide distribution with low levels in some countries and among the highest in others, making generalizations meaningless. Recent evidence from smaller samples in Africa suggests that informal payments of various kinds are common in Uganda (McPake et al., 1999), Mozambique (Lindelow, Ward and Zorzi, 2004) and Ethiopia (Lindelow, Serneels and Lemma, 2003). In all three, patients pay public providers directly for consultations and drugs over and above any formal charges.

Data sources vary with much of the information coming from either household surveys or governance and corruption studies, although some, like Bolivia (2002), Moldova, Kazakhstan (1999) and Poland used dedicated health facility exit surveys ${ }^{5}$, and Albania (2002), Bolivia (2001) and China used province level surveys, and the India data are from a district in Rajastan. Where both large household surveys and smaller studies exist for the same country, the latter always shows higher informal payments. Kazakhstan exhibits dramatically higher payments in the 2002 survey over the 2001 LSMS. Albania's overall LSMS estimate in 1996 was 22 percent, but jumped to 28 and 60 percent, respectively, for outpatient and inpatient care in the smaller 2001 survey. Whether this is due to the greater attention to the issue with dedicated surveys and smaller samples that allow drilling down sufficiently to obtain reliable information on a sensitive subject, or other factors it suggests that some of the broader surveys underestimate the extent of patient payments.

Low levels of informal payments in Peru, Paraguay, Thailand and Kosovo may reflect the existence of and reliance on private sector alternatives that require significant out-ofpocket payments where consumers tend to have more influence on performance. The Czech Republic appears odd given the rest of ECA but consistent with other findings. Public providers with a monopoly position are in a stronger position to charge patients extra for their services.

Kosovars have not had access to public health care for decades and have financed care out of pocket to private providers. Thais too rely on the private sector for some of their

\footnotetext{
${ }^{5}$ The Bolivia survey collected data from 2888 women in 106 municipalities; the Moldova survey consisted of 390 interviews with physicians, nurses and patients in the capital, Chisinau, and two provinces; the Albanian household survey surveyed 3 provinces; the Poland survey was only of Gdansk and Wroclaw cities; and, the Kazakh hospital survey interviewed 1508 discharged patients from three Almaty City hospitals.
} 
health care. The higher rates reported for Colombia and Bolivia, however, would question that explanation since Colombia has a large private health system not too different from Peru's. The differences may reflect different degrees of oversight in public clinics and hospitals, but more in-depth work would be necessary to reach a firm conclusion since the approach to measuring informal payments varies across countries.

\section{Figure 5. Proportion who make Informal Payments Among Users of Health Services, Selected Countries}

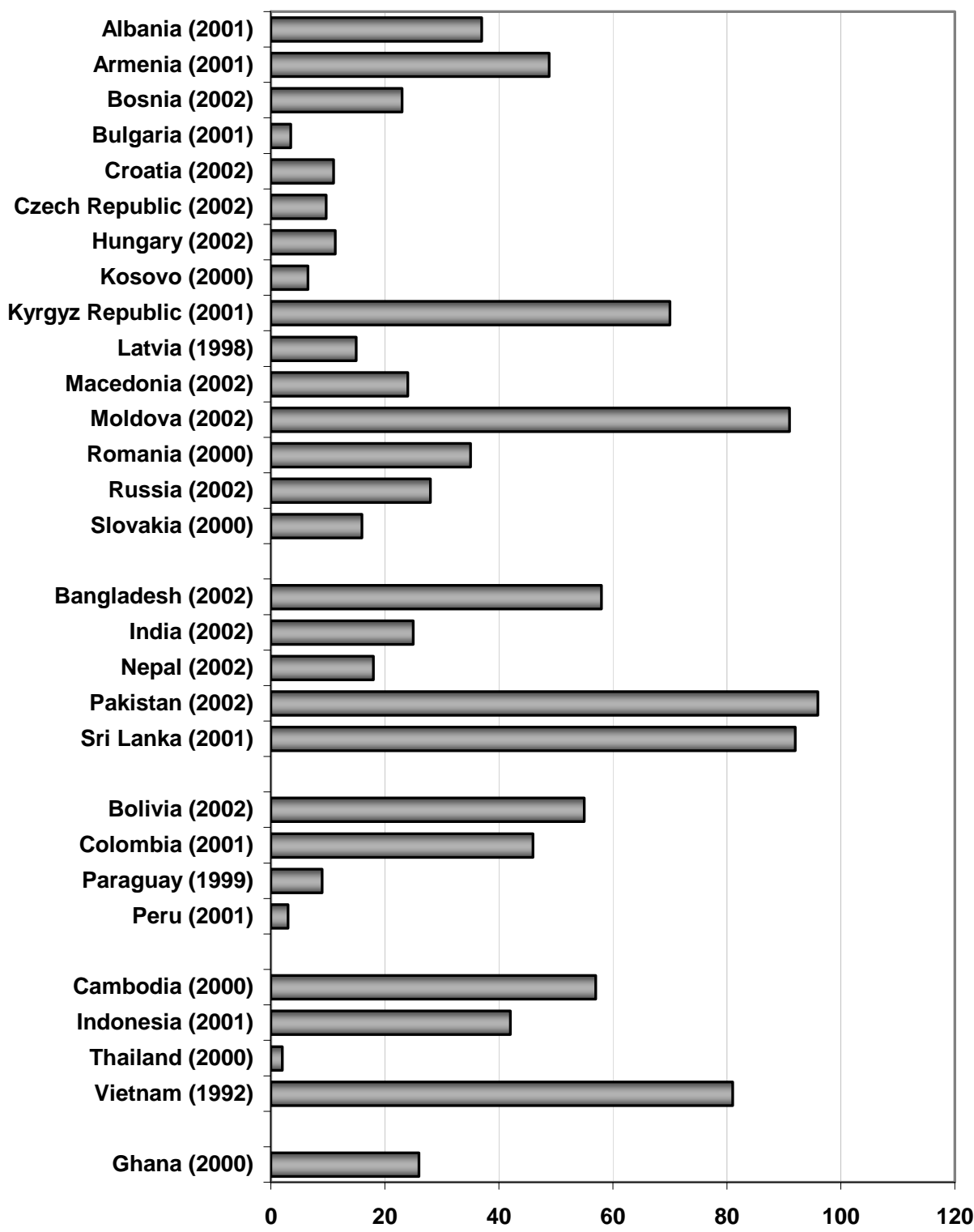

Source: See Source Appendix I 
Figure 6 extends the informal payment distribution to encompass differences in outpatient and inpatient payments and includes some countries from Figure 5. With the exception of Bulgaria, inpatient care is more likely to be financed via informal payments, and often the disparity between the two types of services is dramatic, as is the case with Bangladesh, Tajikistan, Armenia and Albania. Evidence for four Eastern European countries (Czech Republic, Hungary, Poland and Romania) reveals that formal payment are associated with primary and outpatient specialist care and informal payments with surgery and inpatient services (Belli, 2002). Households either feel the need to pay for hospitalizations or providers don't give them a choice insisting on payment if services are to be rendered.

Perception surveys of providers or citizens offer additional insights. In Costa Rica 85 percent of medical staffs indicated that under-the-table payments to physicians were common, and half of patients said they made payments in public facilities roughly equivalent to 50 percent of a private sector consultation. In Bolivia the incidence of informal payments was significantly correlated with perceptions of corruption in specific public hospitals, and 40 percent of interviewed patients acknowledged making illicit payments for care (Gray-Molina et. al, 2001), this is similar to the results of a household survey in 106 Bolivian municipalities reportedly that 45 percent of patients paid informally (Chakraborty et al, 2002). Interestingly, national surveys for Bolivia show that over 60 percent of those interviewed considered health to be corrupt.

A comparative study in five South Asian countries (Bangladesh, India, Nepal, Pakistan and Sri Lanka) found that in all but Sri Lanka most payments were ex ante demands from providers. Bribes are required in all five countries for admission to the hospital, to obtain a bed, and to receive subsidized medications (Thampi, 2002). In Bangalore, India citizen feedback surveys revealed that informal payments were made to ensure proper treatment, but they were typically demanded by providers and 51 percent of those interviewed indicated they had paid bribes in government hospitals and 89 percent in hospitals in small cities, but they also paid informally in the private hospitals (24\%). More 
Figure 6. Proportion of Patients Making Informal Payments by Type of Service, Selected Countries

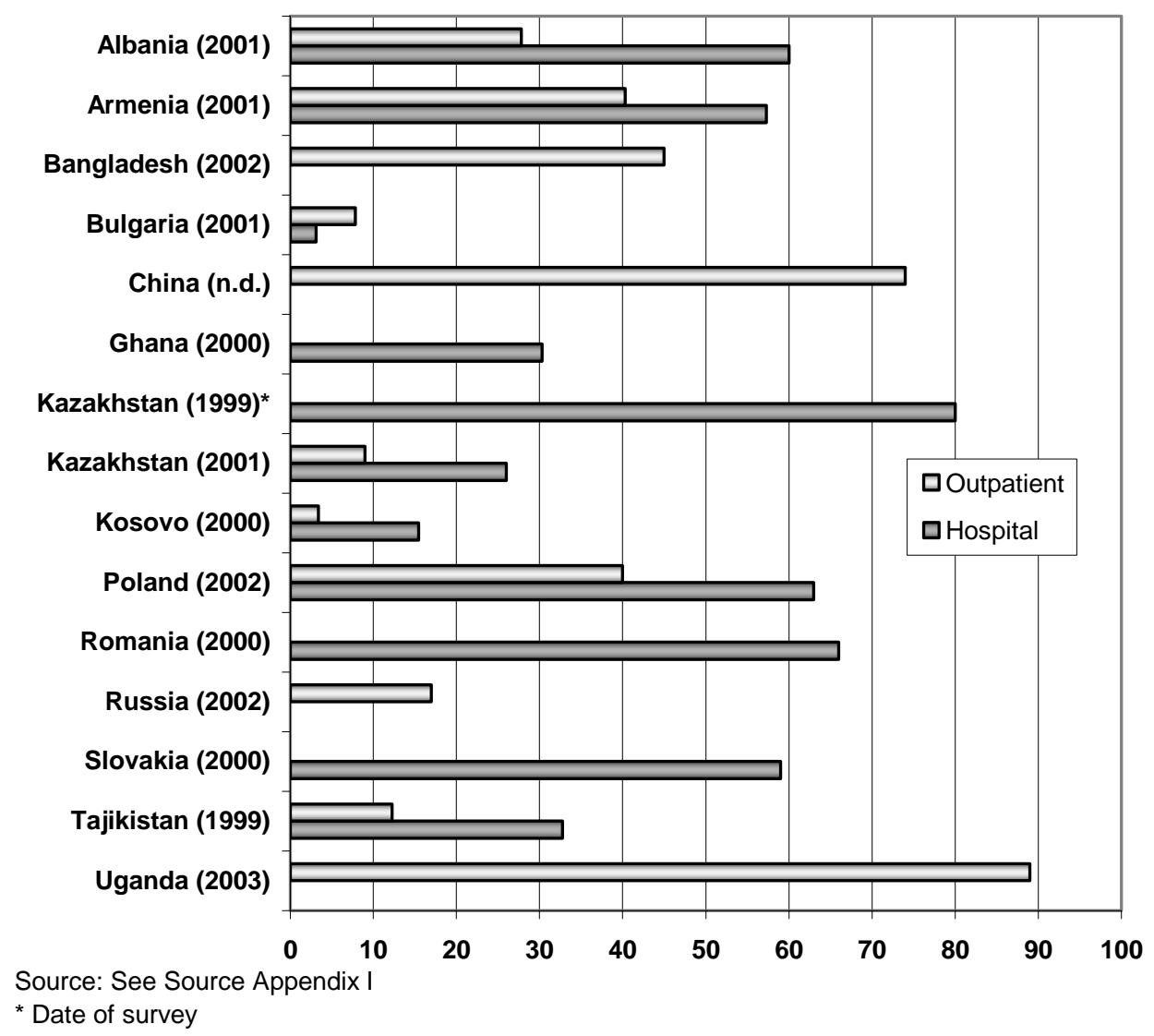

dramatically, bribes were paid to nurses in maternity homes so mothers could see their infants (Gopakumar, 1998). In Albania among the 60 percent of patients who received care 43 percent said the gift was requested (World Bank, 2003a). Using focus groups of patients and providers Shahriari, Belli and Lewis (2001) explain the virtual market for publicly provided care in Poland. Informal payments have become the way to obtain the services of specific physicians, with pricing reflecting reputation and demand. It is an implicit form of insurance for possible future needs, and prices are commonly known. Thus the process of negotiation and payment for health services may be informal but it has become a very sophisticated market in Poland.

The motivations of health staff and patients in relying on under the table payments are strong. Physicians argue that low pay, irregular salary payments, lack of government attention and the need to keep services going requires drastic action, and patient contributions offer the only source of funds to fill the gap (Bloom Han and $\mathrm{Li}, 2001$; Belli, Shahriari, Lewis, 2001; Lindelow, Serneels and Lemma, 2003; Kutzin et al., 2003). Patients on the other hand also see low pay as an impetus to contribute, but traditions of gratitude as well as concerns for some future need also play a role. 
In Ethiopia feedback from policymakers, experts and health workers revealed that inappropriate payments are rife in the health sector. Patients typically must pay for every service and each item, from registering to paying bribes for changing bed sheets to drugs and supplies (Lindelow, Serneels and Lemma, 2003). Similar reports of itemized charging emerged from qualitative work in Georgia (Belli, Shahriari and Gotzadze, 2004) and Poland (Belli, Shahriari and Lewis, 2001) where there too the public system has become a fee-for service entity. Qualitative studies explore this in some depth. Consumer confusion about the official or unofficial nature of payments is common. Patients pay but they don't always know why and they often do so at multiple locations or for different “services” (Belli, Shahriari and Gotzadze, 2004; Narayan, 2000; Killingsworth et al., 1999).

Multivariate analysis sheds further light on some of the underlying motivations for informal payment as well as whether patient revenues are well spent. In Kazakhstan Thompson's (2004) econometric analysis of patients discharged from three hospitals in Almaty City concluded that informal payments made in the admission department before treatment, and the amount paid subsequently at both admissions and hospital wards shortened admission time for surgery. He found longer lengths of stay associated with payments to both the admission department and directly to individual providers on the wards, and perceived patient quality increased with the amount paid informally. These results confirm the assumption that patients pay to receive more attentive and "higher quality" care as they perceive it. Longer lengths of stay do not necessarily mean better clinical care, but shorter waits, longer hospital stays and better treatment by medical staff tend to be valued by patients. In Kazakhstan paying ensures that health care meets the demands and perceived needs of patients.

Of concern is the relative cost of the services to patients, and numerous studies point out the impact on the poor. Figure 7 summarizes the available data showing the average cost of an outpatient visit or hospital admission as a percent of half monthly income, roughly equivalent to median income (source). The level of inpatient payments far exceeds the amounts paid out for outpatient services and numerous studies document the extent of hardship some households face in meeting these costs. Inpatient costs can exceed annual family income forcing the sale of assets or the accumulation of debt in order to afford care (Lewis 2000, 2002; Falkingham 2002, 2004; Killingsworth et al., 1999). Selected studies in China of "red packages" paid to providers report that payments average between 140-320 yuan per hospital visit (US\$16-36), with referral hospitals averaging 400 yuan (US\$44), roughly 90 percent of half monthly income (Bloom, Han and Li, 2001).

Two studies in Albania showed different aspects of the informal payment issue. The analysis of a three province survey showed that rural residents were more likely to pay for services though they paid about the same as those in other income brackets when they did pay, and income had no effect on the probability of having to pay (Hotchkiss et al., 
Figure 7. Average Informal Payments as Percentage of Half-monthly Per Capita Income, Selected Countries (Int'I \$ PPP)

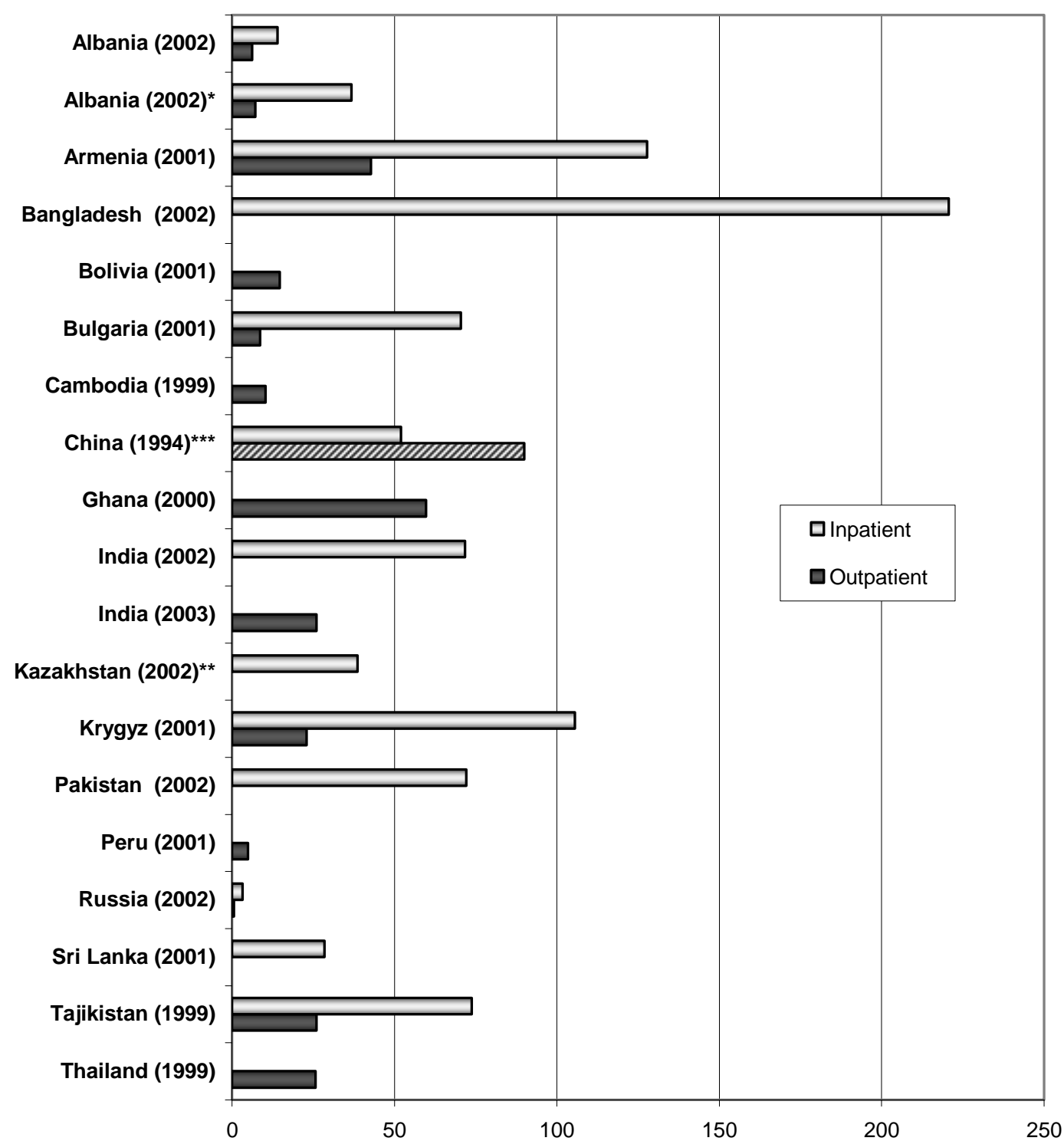

Sources: World Bank LSMS; Murrugarra 2003; Falkingham 2000 and 2001; Transparency International 2002 ; World Bank 2000b, 2000d, 2001a; Phongpaichit 2000; Bloom, Han and Li 2001, Banerjee and Duflo (2005).

*Survey of 2000 housholds in three Albanian provinces

**Based on hospital exit surveys

***Percent calculated as average across various studies. Striped bar indicates referral hospitals. 
2005). Estimates of the price elasticity of small increases in the price of health services using a national representative survey found almost no effect, indicating that patients are not particularly price sensitive in Albania (World Bank, 2003a).

Exemption for fees offers the potential for husbanding scarce resources for those least able to afford health care. Many systems have instituted such procedures to retain the benefits of co-payments without unduly burdening the poor (World Bank, 2004). Evidence on effectiveness, however, suggests problems with the approach. In Bangladesh data from interviews and observation in a sample of four hospitals showed that 75 percent of the time the lowest income group paid the least amount both officially and unofficially. In the outlier institution the poor paid more than the wealthiest group but the same as or less than the middle income patients. Payments are also standardized and routinized with specific time periods for charging during inpatient stays rather than at discharge (Killingsworth et al, 1999).

In Rajasthan, India patients regularly pay for "free” outpatient care, though the poorest patients pay 40 percent less than the highest income patients, though it should be noted that in this part of India everyone is poor it is simply a matter of degree. On average 7.3 percent of total household spending goes to paying for health care (Banerjee, Deaton and Duflo, 2004). In Uganda exemptions were extended to the politically powerful and those overseeing the local health care program (McPake et al, 1999), a perverse version of exemption meant to ensure equal access but in this case subsidizing the better off. Central Asia's experience has not been encouraging either with minimal exemptions for lower income patients (Falkingham, 2004). Evidence from Kazakhstan showed that for major illnesses the lowest income households spent more than twice their monthly income for health care while the wealthiest households spent the equivalent of half their monthly income reflecting the lack of exemptions for the poor (Sari, Langenbrunner and Lewis, 2000).

Informal payments are much more widespread than commonly thought. Indeed, donors and governments have urged banning user charges in the interests of equity in access to health services. Sweeping removal of a reliable source of revenue for equity reasons means that those who can and cannot pay receive free care. However the strategy could simply encourage under-the-table payments from both sets of patients since patients already pay and in some cases can afford treatment. While there is some suggestion from Kyrgyz Republic (Kutzin et al, 2003) and Cambodia (Barber, Bonnet and Bekedam, 2004) that instituting formal fees can serve to curtail informal payments, the impact of removing fees has not been assessed. Anecdotal evidence suggests a rise in informal arrangements, but documentation has not confirmed this.

\section{E. Mismanagement in Health Care Service Delivery}

Often irregularities and poor governance simply stem from poor management. Where incentives for strong performance either don't exist or are undermined by ineffective management it is not surprising that productivity and performance suffer. For example, if staff advancement caps after a single promotion, a common pattern in many countries, 
then the incentives to excel are diminished. By the same token the inability to fire public sector staff even in the face of embezzlement or nonattendance erodes managers' authority and the public sector's ability to hold staff accountable. The lack of carrots and sticks dis-empowers public management and thwarts efforts at accountability.

Evidence on mismanagement is spotty. The core issues include human resource management and supervision, basic subsystems function (e.g., procurement, drug logistics), efficiency of fiduciary transfers, input availability, and satisfaction of the target population.

Overall management of health systems, hospitals and clinics typically fall to physicians, few of whom have the training or experience necessary to effectively carry out their jobs. This poses a major problem in Turkey as they move to reform the health system (World Bank, 2003c), and was at the heart of ineffective service delivery in the Dominican Republic (La Forgia et al, 2004). Disincentives to good performance often are due to rigid civil service rules that limit promotion and pay differentials that could be used to reward superior performance. At the same time low productivity or outright abuses can go unnoticed (Lewis, LaForgia and Sulvetta. 1992).

Low wages also lead workers to seek additional employment outside government. In Kogi State, Nigeria, 42 percent of the staff had not been paid their salaries for more than 6 months in the past year (Das Gupta, Gauri and Khemani, 2003), converting staff into virtual volunteers and eroding the credibility of the health system. In addition to the Nigeria state, reports from Ethiopia, Mozambique and Uganda (Lindelow, Serneels and Lemma, 2003; Lindelow, Ward and Zorzi, 2003; Azfar and Gurgur, 2001) indicated that the need to have additional sources of income effectively compromised providers' ability to carry out their public duties on the scale intended. In qualitative surveys health workers said they missed work or cut short their hours to devote time to other economic activities. Another study in Nigeria showed that the greater the lag in paying salaries the more likely health workers were to engage in pharmaceutical sales and seek other employment in the private sector (Khemani, 2004). Family survival therefore plays a role in absenteeism and low productivity.

Evidence from a number of countries suggests that vague and poorly understood policies, uneven recordkeeping and minimal use of such information contribute to poor management. An assessment in Nigeria found a low level of knowledge among Federal Ministry of Health (FMOH) staff regarding standard procedures and regulations, and current budget allocations. Moreover, current budgets and expenditures did not correspond (World Bank, forthcoming). In Uganda staff records were inadequate. At the facility level only 56 percent of the staff are to be found in district records, but at the district level there were an additional 109 staff (out of a total of 465) who do not show up on facility rosters (Lindelow, Reinikka and Svensson, 2003). In Honduras 2.4 percent of staff were "ghost" workers and 5 percent of staff had unilaterally moved to other locations (World Bank, 2001f). 
Poor recordkeeping capacity and failures to require acceptable reports in Mozambique (Lindelow, Ward and Zorzi, 2004) undermined health care delivery and regular availability of inputs. In Nigeria, existing management information systems were deemed ineffective due to complicated and obscure reporting requirements, incomplete record keeping and low capacity (World Bank, forthcoming). Drug management in Costa Rica, a well run middle income country, exhibits particular weaknesses in logistics and distribution attributed to flawed information systems and inadequate monitoring (Cohen, 2002). Each of these represent deficient aspects of recordkeeping that compromise efforts at management.

Poor management also appears to signal corruption in some instances. In Bolivia multivariate analysis showed a significant association between longer waiting time and corruption indicators (Gatti, Gray-Molina and Klugman, 2003), and in the Philippines perceptions of corruption in public health services discouraged use of public facilities, particularly in poor communities (Azfar and Gurgur, 2001). Corruption no doubt is associated with bad management, the question remains as to whether and how management flaws lead to corruption.

This brief review does not do justice to the complexity of the issue, and more attention to the problem of incentives and management are warranted. Although a chronic weakness of health systems, management is critical to performance and improved effectiveness. Ensuring the availability of funds, hiring and deploying staff, maintaining basic record systems, and tracking facility performance are the basic ingredients for improving management and overall health care delivery.

\section{Policy Options for Promoting Better Governance}

Improving governance poses an important challenge to governments in transition and developing countries, but there are good examples of things that can be done based on actual experiences. This section is divided by category to summarize the evidence and link these lessons to specific agendas. Accountability and incentives serve as threads across the components because they represent the keys to better policy and outcomes.

Key accountability measures include (i) information on performance and impact, (ii) the ability to audit, (iii) the authority to reward performance, and discipline, transfer and terminate employees who engage in abuses; and (iv) answering to stakeholders on the performance of public services. Accountability tends to be absent due in part to measurement problems but also to minimal management, oversight or evaluation of performance. The high demand from patients for diagnosis and care when they fall ill, and the difficulty in generalizing across medical conditions further complicate oversight and accountability. 


\section{A. Improving Government Effectiveness}

The health system that delivers health care is only as good as its management. This section focuses on government initiatives and management tools that can raise effectiveness and performance.

Adequate incentives for health professionals lie more in the structure of the health care system and its financing than in limited actions that fix existing arrangements. Fundamentally money needs to follow patients at least in terms of tying medical staff time to specific patients. Paying providers whether they see (or are assigned) patients or not, and compensating under and over-performance equally is both unfair and unlikely to build the trust needed in a public health system. How that is accomplished is the challenge, and there are options.

The exception to money following patients may be capitated payments where physicians receive a fixed prospective payment for each patient and extends services as needed. It has been shown to be highly effective at providing the necessary incentives for providers, but typically is combined with clear management and oversight to ensure accountability. Physicians who don't see patients under capitation are managed to assure that they comply with requirements of contracts, so in the end money does follow patients.

Adjustments to pay and benefits, clear criteria for hiring and promotion, defined discipline for misconduct and adequate training to equip workers with needed skills foster a functioning health system. How providers are paid has dramatic effects on performance, as evidence from the OECD countries attests. Payment methods are the cornerstone of incentives for productivity and performance and increasingly developed countries have sought alternatives or at least complementary means to reward performance and productivity.

In most developing countries physician compensation remains salary based. A review of the limited literature on the effect of salary earnings on physician clinical behavior across the OECD concluded that physicians whose earnings are based on salary rather than feefor-service, bonus payments or capitation showed lower productivity, lower levels of care and higher wound rates from surgery. However, salaried doctors facilitated cost control, a major concern in OECD health systems (Gosden, Pedersen and Torgerson, 1999).

Low wages represent one area of potential temptation for corruption. Where earnings are low individuals have second and third jobs, but they also perceive that low wages entitle them to demand contributions from patients. Civil service reform is often required to address egregious structural problems related to postings, promotion and pay, but the health sector can also serve as a pilot to launch improvements that stimulate better performance. Alternatively experimentation with other payment arrangements may prove more effective.

In Bolivia corruption was lower where management was stronger and some form of oversight of staff existed, in this case, frequent written evaluations of performance, key 
inputs for rewarding and disciplining staff (Gatti, Gray-Molina and Klugman, 2004). In education, inspectors were associated with lower absenteeism in some cases, and it may apply in health care. However, business effectiveness studies in the FSU show how inspectors can undermine the system through bribes to certify acceptable performance, so it is important to ensure that such arrangements are working as intended if they are adopted.

In a recent experiment, Leonard (2005) assesses the importance of training and incentives in determining physician performance in Tanzania across a sample of public and private providers. He concludes that while ability is important, institutional incentives, particularly the ability to hire and fire staff, are far more powerful than education or experience in explaining the quality of care provided patients, offering an empirical basis for the priority of putting in place incentives to foster improvements in health care.

A fundamental initiative is the establishment of clear procurement and contracting rules. Evidence for Argentina and Colombia shows a potential role for effective oversight as discussed. To effectively achieve such results requires existence of clear rules, effective oversight to detect problems, enforcement of rules, and rewards and punishments for good and unacceptable behavior, respectively. The lack of minimal managerial order and oversight are fundamental weaknesses in many public health systems which permit such abuses. In fairness, however, battling these kinds of problems persist in even the wealthiest countries and relentless effort are required to control corrupt practices.

In the Philippines multivariate analysis found that the frequency of audit by central government and autonomy of local government increased immunization coverage, suggesting that local governments can benefit from authority, and auditing will further encourage responsible public performance (Azfar and Gurgur, 2001). In Madagascar, sanctions for misuse of funds led to systematic following of financial procedures. Most important among sanctions was criticism from supervisors and transfer to less desirable locations. Though the effect of accountability is diluted by the fact that the most common reasons for transfer is displeasing local officials without discussion or vetting of the merits of the transfer, frequent audits of financial records combined with consequences for staff were successful in improving financing management, a cornerstone of government effectiveness (Brinkerhoff, 2005).

The nature of accountability and how to structure incentives is not apparent from the evidence assembled here. Ostensible community oversight has been assessed in Bolivia, Madagascar, the Philippines, Uganda. The centralized hiring, promotion and deployment of public health workers in all countries effectively neutralizes the role of local supervision. If the consequences of absenteeism, taking of bribes and stealing of drugs are beyond the authority of local boards or community oversight bodies then those institutions may bring the community together but they will have no influence over the centrally managed health staffs, or service delivery responsiveness and access. 
Even where systems exist to promote accountability it does not necessarily mean that they are effective. In Jigawa state in Nigeria hospital management committees meant to oversee and advise hospital managers rarely met, were unclear on their responsibilities, and had little involvement with strategic planning, targeting or budget control (World Bank, forthcoming). In Madagascar, the fact that local committees were powerless beyond moral suasion led providers to ignore their hollow authority and instead respond to supervisors who had a say in their destiny (Brinkerhoff, 2005). To be effective community leaders need authority, and at the same time they need to be accountable to the local citizenry.

Local control where it goes beyond simply oversight holds promise. Under the "Bamako Initiative" that gave communities in selected African countries control over health facilities in exchange for sharing the financing burden showed impressive health status improvements in at least three countries. In Ceara, Brazil the state instituted a health worker outreach program with hired health outreach workers under contract to the state, and handed responsibility for supervision to municipalities. Local control led to better health in the communities covered by the new state program (sources). In Bolivia corruption was lower where local organizing groups were active (Gatti, Gray-Molina and Klugman, 2003). In contrast local control proved ineffective in Nigeria, Madagascar and Uganda (World Bank, forthcoming; McPake et al, 1999; Brinkerhoff, 2005) leaving the issue unresolved, but more experimentation and systematic evaluations can help address this.

Strategies to control informal payments entail both finding alternative sources of funding and better management. Raising official fees as a substitute for under-the-table payments showed positive effects on patient payment and utilization in two pilot programs: in two regions in the Kyrgyz Republic, and a major referral hospital in Cambodia. In Kyrgyz Republic formal fees reduced informal charges as confirmed by both multivariate analysis and data which showed the proportion of patients making direct payments to providers declined from 60 percent to 38 percent while informal payments for the country as a whole rose to 70 percent. In-kind spending by patients for food and linens in the pilot regions with formal fees remained constant but spending for drugs and medical supplies declined by over 50 percent though there was no change in the country as a whole. That combined with insurance payments helped to make health care more affordable and quelled under-the-table payments (Kutzin et al, 2003).

In Cambodia reorganization of hospital staffing combined with a transparent official fee policy, clearly designated exemptions, and retained fee revenue that supplemented physician salaries at levels comparable to those earned under the informal arrangements led to more reliable pricing, stable revenue and higher demand. Focus groups identified the deterrent of informal payments to health service use, and the subsequent predictability and equity adjustments improved access without compromising utilization or hospital revenue, the latter a critical component of compensation given salary levels (Barber, Bonnet and Bekedam, 2004). Two instances do not allow sweeping conclusions, but the fact that substituting legal for illegal payments and allowing the points of service to retain revenues proved effective suggests that it is a strategy worth pursuing further 
Addressing some of the incentives behind informal payments provide options for reform. Some alternative policies include: standardizing quality and access (e.g., waiting time), allowing and promoting alternative financing mechanisms through the private sector (e.g., private insurance arrangements), and, within the public sector, balancing the number of staff and resources so as to have fewer positions with higher pay. As discussed elsewhere higher pay will not necessarily address corruption by itself, but paying wages that are appropriate to existing labor market conditions, prohibiting side payments and holding providers accountable could together encourage more transparent and fair transactions, and offer incentives for better provider performance. Although it is expensive for countries to raise wages in public health care services, a reform that regularizes and improves pay has the potential to raise productivity. Higher productivity, in turn, would make it possible to provide the same amount of services or more, with fewer workers, thereby offsetting some of the expected increase in the total wage bill. In addition, greater transparency in all fiduciary functions would improve fairness and bolster effectiveness.

In Venezuela, a study of public hospitals found that theft and unjustified absences declined with greater accountability, although the rate of approved absences rose, so reforms can be effective but management objectives can sometimes be too narrowly defined (Jaen and Paravinski, 2001). The issue should not be absences per se but performance and both management and accountability mechanism need to focus on these.

Having government contract out services can often improve performance of publicly subsidized services, partly because holding contractors accountable is far easier than doing so with public workers. Often government has few incentives to offer public servants given rigidity in most civil service rules, but retains leverage over contractors. Nonetheless contracting out is far from a panacea as it means developing regulatory capacity which varies from the standard tasks of providers and managers who operate points of service. Experience in Haiti (Eichler, Auzilia and Pollock, 2001), Cambodia (World Bank, 2004) and Central America (La Forgia, 2005) suggest that contracting out can work even in the lowest income environments, the challenge is ensuring continued oversight and accountability of contractors. To date only the four Central American cases have a track record across elections.

Consumer satisfaction surveys help build accountability. Exit surveys, mini-household surveys or focus groups to elicit responses help gauge the strengths and weaknesses of public programs. Including these in annual reporting up the chain of command, and encouraging points of service to use these for management purposes would provide benchmarks for making public services more responsive, and bolstering their impact and effectiveness.

\section{B. Controlling Corruption}

This paper has described the wide range of irregularities that characterize health care services in developing countries and suggests that corruption flourishes where there are 
no standards of performance, oversight, or penalties for unacceptable behaviors. The options discussed here have a track record, but the policy context and actions taken by officials provide the needed detail that explains why certain policies were found effective. Policies themselves are necessary but not sufficient as enforcement is equally important.

Game results from an experiment in Ethiopia used to determine temptation for corruption concluded that higher pay curtails the level of corruption, but only slightly, and that public servants appear to expropriate fewer resources when observability is higher, indicating that better oversight and exposing of inappropriate behavior can have a dampening effect on corruption (Barr, Lindelow and Serneels, 2004). In short, the potential for getting caught offers a strong disincentive for corrupt behavior.

Corruption in the health sector is unlikely to be an isolated public service failure. Addressing irregularities across the functions of the sector - construction, procurement and distribution of drugs and supplies, deployment of underpaid staff, under-the-table payments - requires an integrated, mutually reinforcing anti-corruption strategy with strong political backing and a willingness to take a position and follow through. Indeed, it may well require a government-wide anti-corruption agenda, as Poland has undertaken. Even there it isn't enough to remove informal charges as the studies discussed here indicate. Making clean government a priority allows irregularities to be identified and addressed, which bolsters efforts in the sector to put in place effective oversight and detection, and endorses disciplining corrupt practices once detected. Without the willingness to act on identified corruption countries are unlikely to be able to control such practices.

Higher salaries for public sector workers are frequently proposed as a way to curb corruption, but the evidence is complicated and not straightforward. Moreover, as discussed above, there may be better means of compensating health professionals. In a study of the effect of civil service pay on corruption using cross-country regression and controlling for a wide array of factors, showed that wage levels could affect corruption but must rise dramatically to seriously reduce corrupt behavior (Van Rijkeghem and Weder, 2001). Although challenged on their corruption measures, Rauch and Evans (2000) find no effect on corruption of higher public sector wages, and instead propose that employment security, recruitment and promotion criteria, and management are of greater importance than salary increases. A study in Venezuela found a perverse effect with higher wages correlating with more corruption. Jaen and Paravinski (2001) interpret this as corrupt wage earners capturing wage setting through either influence or bribes. In sum, despite the view that salary adjustments will solve corruption the evidence suggests that while wage levels may play a role in controlling corruption it is not guaranteed and other changes need to accompany higher earnings.

An issue is whether the necessary increases required to eradicate corruption are affordable and realistic for most low income countries. Some increases may be warranted but it would also mean staff reductions to accommodate higher pay. These are 
considerations that should accompany civil service reform plans meant to raise salaries and curb corruption.

The absence of basic information, regular audits and monitoring evidence define an environment that invites misconduct. As Colombia implemented Law 100 reforming its health care system it unearthed extensive corruption and mismanagement in reporting and record keeping in public programs. In response the Ministry of Health set up a nationwide database for data matching and payment controls to identify and correct abuses that were resulting in paying "ghost" workers, among other problems. That combined with a multimedia campaign informing citizens of their rights and obligations under the newly reformed system provided a segue-way into better oversight and involvement of citizens (Soto, 2002).

Drug procurement poses multiple challenges and Chile's experience is instructive in how to institute reforms that serve multiple objectives. Chile's drug and medical supply system run by the government, CENEBAST, was plagued with poor management, frequent stock outs and overstocks of other medicines. The reform was built around a shift from a rules-based system to one grounded in transparency and good incentive structures. Its main components were: (1) introducing electronic bidding for pharmaceuticals; (2) reform of CENEBAST to change its mandate to procurement agent for hospitals and other providers who define drug priorities; and (3) information dissemination that let it be known that pharmaceutical procurement would be under scrutiny. An important element of the institutional reform was allowing other agencies and the private sector to purchase, store and transport drugs, removing CENEBAST's monopoly position.

The reform reduced information asymmetries between providers and the procurers of pharmaceuticals. and produced clear and fair rules resulting in bids from a broader spectrum of companies and lower prices for government hospitals and clinics. Overall in 1997, US\$ 4 million was saved just in pharmaceutical purchases (Cohen and Montoya, 2001).

Nigeria has taken an aggressive stance on the issue and has rooted out considerable illegal manufacturing, identified substandard importation, recalled all "repackaged" drugs, and ensured that drugs meet a basic standard of potency, labels are clear and correct, distribution is achieved through legal channels and oversight of provision, storing and handling are systematically regulated. Evidence from elsewhere, however, is scarce as this is an area where little action has taken place at the country level and/ or these have not been evaluated. Middle income countries, like Costa Rica, tend to deal with the problem more aggressively (Cohen, 2002), but regulation remains inadequate given the ease and lucrative nature of drug corruption.

More information to citizens about resource flows from central and local governments and clarity on the roles and responsibilities of local authorities. Though it requires better data on performance, tying local outputs and resource allocations from central government (conditional resource transfers) offers a structure to undermine corruption and improve service delivery. Where citizens are informed and empowered to oversee 
the process, they have both a financial stake and the tools to enforce policies. Without the latter, citizens will be far less likely to view involvement as worthwhile.

Citizen report cards offer another possible means of engaging citizens in oversight to improve the quality and integrity of public services. Pioneered in public services generally, report cards have not yet been assessed as a means of improving health services, but through investigative studies they equip citizens with information on the shortcomings or failures of health services. Use of press reports based on the studies provides both evidence (rather than anecdotes) as well as a public forum for debate, which together help localities identify where change is needed (Gopakumar, 1998; World Bank 2004). Like information more generally, having authority to take action is the sine qua non of effectiveness in report card use.

\section{Voice}

Although not strongly associated with health outcomes, voice captures citizens' ability to get information, challenge government and ensure that services meet their needs. The record is mixed on the effectiveness of voice in improving service delivery, but some useful lessons emerge.

Information is necessary but not sufficient for citizens' to be empowered. Without the information citizen action can only be random stabs at perceived problems. Information allows concerted action. In Uganda informing citizens of fiscal transfers from the central government by posting budget receipts on school doors and announcing them in the local press led to significantly higher receipts, a more informed public and a better financed school system (Reinikka and Svensson, 2004). Similar initiatives would apply in health since local health districts are financed through central allocations. In Colombia regular press reports on procurement regularities reduced overpayment by almost 200 percent. Despite the scope of these findings, conclusions are tentative given the small number of cases, but these suggest promising directions.

The evidence on the role of local voting is uneven. It appears to have a minimal if any effect on corruption at the local level, though the number of studies is small and therefore not necessarily representative of the developing world. In Bolivia no association was found between perceived corruption and voter turnout, participation of citizens in cultural and religious associations (a proxy for social capital) or the number of NGOs, the institutions that are meant to represent citizen voice in municipal budget councils (Gatti, Gray-Molina and Klugman, 2003).

In the Philippines and Uganda surveys showed that despite high election turnouts for both local and national elections voter numbers were unrelated to corruption levels, and electoral preferences in both countries were shaped by other factors. A multivariate analysis of the Philippine data showed that low levels of corruption (as measured by an index of household and public official responses) were correlated with voting in local elections and reading national newspapers. Moreover, in both countries civic activities were common, suggesting that citizens remain active in government despite a corrupt 
environment. That environment may help to explain why voting had little effect on corruption (Azfar, Kahkonen and Meagher, 2001). Other factors clearly have a stronger influence on voter choices.

These results lead to the tentative conclusion that voice can take many forms and none by itself will necessarily lead to the effective control of corruption. However, the expression of voice via the press or direct community involvement appear to be more powerful tools than voting in influencing public performance. Public service delivery does not affect voting patterns or candidate selection sufficiently. Voting may be too blunt of an indicator, one that captures a range of interests of constituents. Health will only predominate if it is the pressing issue of the moment. Otherwise other concerns drive voter preferences. Some of this may be due to entrenched corruption where localities regardless of their oversight simply do not have enough clout to influence public sector behavior. Where hiring and promotion remain centralized, local voice will have less effect in any case. Popularity of candidates, other factors that appeal to voters and insufficient evidence on things like corruption no doubt play a role, but it is difficult to be definitive given the paltry evidence and the complexity of the issue.

Community oversight can work but it doesn't always. In Boliiva corruption is lower where local oversight groups are active "suggesting that bottom-up accountability can be effective in keeping corruption in check" (Gatti, Gray-Molina and Klugman, 2004). In contrast, Uganda's Health Management Committees expropriated drugs and supplies providing virtually no oversight or support to local service delivery (McPake et al, 1999), and in Nigeria village development committees and PHC Management Committees had little impact on health care performance largely due to their lack of authority (World Bank, forthcoming).

Efforts by a local NGO in Kenya attempted to empower communities to monitor teacher attendance using both reports to the school hierarchy on performance and community awarded prizes to the best performing teacher. Neither served to improve attendance, despite the active participation of communities. In contrast, an NGO experiment in India using cameras to record teacher attendance, which are tied to compensation bonuses resulted in a dramatic improvement in delinquent behavior (Banerjee and Duflo, 2004). It may be that voice has less weight in influencing behavior than more remunerative approaches combined with air tight monitoring. As cellular phones become cheaper and more functional in rural areas photos sent electronically offer another possible alternative means of monitoring progress at the local level.

While voice matters in many service delivery instances, its role in health seems to be less straightforward. The specialized nature of medicine, the heterogeneous products of the sector and the status of physicians in most societies complicates oversight by communities, and voting is a relatively blunt instrument for influencing the quality and responsiveness of health services. 


\section{Conclusions}

The review of country evidence and the examination of the cross-country factors that influence performance (and to some extent outcomes) in health care suggest that governance plays an important role. If the health system is not governed well, health workers are absent, patients pay illegal fees, and basic inputs are stolen without any consequences for those who mismanage or corrupt the system, performance of health services will be poor and population health will suffer.

Many health systems rely on anecdotal evidence to guide policy. What this paper has attempted to do is provide the evidence and outline the major challenges facing health systems, dealing with issues typically ignored or unaddressed. Better country level data can help in diagnosing the problem and some of the experiments here may offer possible solutions.

The second conclusion is that the returns to health investments may be very low where governance is not addressed. Even with a time lag, investments such as those seen in Uganda, Dominican Republic and Ethiopia, countries for which detailed data exist, will be unlikely to see high returns from public health spending. As incomes and education rise a shift to private provision may offer higher returns -- something that is already underway in the Dominican Republic and India, and something likely to occur in lower income countries where governance is poor and the private sector steps in to replace public service. There may be individual returns to the shift, but equity objectives are likely to suffer. Even the poor select to pay significant amounts of disposable income to obtain private care, a sad commentary when public services go underutilized.

Third, a countries' health system is the institution that must be engaged and on the front line if governance is to improve government effectiveness and control corruption in the sector. Without bolstering the key institution for the sector it is unlikely that the goals of reducing poverty, mortality and morbidity can be achieved. The evidence here points to serious problems of governance across the globe in developing and transition countries, which thwart the goals.

Finally, achieving the dramatic and permanent declines in mortality envisioned by the Millennium Development Goals is doubtful unless governments shift their attention to the institutional factors that affect performance in the health sector. A dysfunctional environment limits the chances that more funding can have an impact, and much of the discussion above highlights situations that will not necessarily benefit from large increases in funding unless more is done to bolster the capacity of the institutions expected to implement the agenda. Funding without the necessary institutional strengthening could lead to perverse results, and assistance for both governance and financing will be needed in the health sector.

This review demonstrates that as a first attempt to compile evidence, what is striking is the fragmented nature of the evidence is surprisingly fragmented. It also shows the lack of meaningful indicators for cross country comparison, and an absence of critical data at 
the country level. One issue not discussed but obviously of importance to policy is the variations in government capacity across income levels. Reforms in Chile apply to many countries, but some will have resources too limited to take on similar reforms.

Nonetheless, there are elements that can be adopted. For example, the Chilean drug procurement reforms in electronic bidding and institutional reform of drug purchasing agencies are well within the purview and capacity of most countries, even if the shifts are more modest in scale. Reforms in any case are entirely country specific given the political nature of health care. What the examples provide here are possible directions, all of which will necessarily be adapted to country circumstances.

Even without these important inputs simply having benchmark countries with which to compare countries would strengthen the cross country evidence. Acceptable indicators, benchmarks and additional attention to systemic issues would enable more robust indicators of overall performance, which in turn would inform policymakers and donors of challenges and opportunities for improving health institutions.

What needs addressing is the context and framework under which health systems function. First and foremost is better accountability. Greater professionalism among health staff, effective training and supervision of staff at all levels, routine audits of all aspects of fiduciary transactions, improved records and recordkeeping to provide systematic data to managers and the bureaucracy, and procedures that can facilitate service delivery in a more user friendly fashion all need to be addressed. Running hospitals, clinics and other points of service in the manner of a business or of a ministry of finance would be particularly helpful. The discipline implied and the need to be accountable provides the incentives that improve productivity, patient satisfaction and performance. That is where health systems need to move.

Incentives that raise performance - ensuring appropriate, targeted training so health professionals are equipped to do their job; linking pay and performance; reviewing and auditing performance; improving recordkeeping; and upgrading logistics for drugs and supplies - need to be an integral part of health systems. Investments in institutions require these kinds of initiatives, and donors are in a position to foster such improvements with both funding and advice to oil the wheels of progress and support the emergence of strong institutions.

Where public services are free or subsidized, with the intention to promote access and utilization of vital health services, the abuses related to lack of drugs, staff absences and informal payments undermine these objectives as well as the credibility and effectiveness of public services more generally. Without attention to these non-medical issues, clinical care quality and equity in access will be lost, leading to both lower health status and poorly spent public revenues. Addressing these public program failures are critical to effective government to and functioning health care systems. Because good governance promotes economic growth and effective public services, the health sector cannot afford to be sidelined on this agenda. 


\section{References}

Aaby, P. 1995. “Assumptions and Contradictions in Measles and Measles Immunization Research: Is Measles Good for Something?” Social Science \& Medicine 41(5): 673-686.

Alcázar, L and Andrade, R. "Induced Demand and Absenteeism in Peruvian Hospitals.” In Di Tella, R. and Savedoff, W. D. (eds.). 2001. Diagnosis Corruption. Washington, DC: Inter-American Development Bank.

Alesina, A., A. Devleeschauwer, W. Easterly, S. Kurlat and R. Wacziarg, 2003. “Fractionalization.” Journal of Economic Growth 8(2): 155-94. Data: http://www.stanford.edu/ wacziarg/downloads/fractionalization.xls

Anderson, J. 1999. “Corruption in Latvia: Survey Evidence”. ECA Region. Washington D.C. World Bank. Processed.

Anderson, J. 2000. “Corruption in Slovakia: Results of Diagnostic Surveys”. World Bank and the United States Agency for International Development. ECA Region. Washington D.C.: World Bank. Processed.

Azfar, O. 2005. “Corruption and the Delivery of Health and Education Services.” Mimeo. IRIS Center, University of Maryland, College Park, Maryland. Draft.

Azfar, O., and T. Gurgur. 2001. "Does Corruption Affect Health and Education Outcomes in the Philippines?” Mimeo. IRIS Center, University of Maryland, College Park, Maryland. Draft.

Azfar, O., S.Kahkonen and P. Meagher. 2001. “Conditions for Effective Decentralized Governance: A Synthesis of Research Findigs.” Mimeo. IRIS Center, University of Maryland, College Park, Maryland. Draft.

Banerjee, A. and E. Duflo. 2005. “Improving Health-Care Delivery in India”. M.I.T. Working Paper. Cambridge, MA: Massachusetts Institute of Technology.

Banerjee, A., A. Deaton and E. Duflo (2004) "Wealth, Health and Health Services in Rural Rajasthan.” American Economic Review Papers and Proceedings. 94(2) 326-330.

Barber, S., F. Bonnet and H. Bekedam. 2004. "Formalizing Under-the-Table Payment to control Out-of-Pocket Hospital Expenditures in Cambodia” Health Policy and Planning 19(40 199-208.

Bardhan, P. 1997. “Corruption and Development: A Review of Issues.” Journal of Economic Literature 35(3) 1310-1346. 
Barr, A., M. Lindelow and P. Serneels. 2004. "To Serve the Community or Oneself: The Public Servant’s Dilemma.” World Bank Policy Research Working Paper 3187. Washington D.C.: World Bank.

Barro, R. J. and J.-W. Lee. 2000. “International Data on Educational Attainment: Updates and Implications.” CID Working Paper No. 42. Cambridge, MA: Center for International Development, Harvard University. Data: http://www.cid.harvard.edu/ciddata/Appendix\%20Data\%20Tables.xls

Belli, P. 2002. Formal and Informal Household Spending on Health: A Multi-country Study in Central and Eastern Europe.” Harvard School of Public Health, International Health Systems Group. Mimeo.

Belli, P., and H. Shahriari, and G. Gotzadze. 2004. "Out of pocket and Informal Payments in the Health Sector: Evidence from Georgia”. Health Policy 70: 10923.

Belli, P., H. Shahriari, and M. Lewis. 2001. "Institutional Issues in Informal Health Payments in Poland: Report on the Qualitative Part of the Study.” HNP Thematic Group Working Paper, World Bank. (February).

Berg, A. 2005. "High Aid Inflows Case Study: Ghana”. Paper presented at the International Monetary Fund Seminar on Foreign Aid and Macroeconomic Management. Maputo, Mozambique, March 14-15.

Bloom, G., L Han and X Li. 2001. "How Health Workers Earn a Living in China” Human Resources for Health Development Journal 5(1): 25-38.

Brinkerhoff, D. 2004. “Accountability and Health Systems: Toward Conceptual Clarity and Policy Relevance.” Health Policy and Planning 19(6): 371-379.

Brinkerhoff, D. 2005. “Pro-poor Health Services in Madagascar: Decentralization and Accountability”. Paper presented at Global Health Council Annual Conference (may-June).

Brueckner, J. 2000. "Fiscal Decentralization in Developing Countries: The Effects of Local Corruption and Tax Evasion”. Department of Economics and Institute of Government and Public Affairs. Urbana, Illinois: University of Illinois.

Carasciuc, L. 2001. “Corruption and Quality of Governance: The Case of Moldova”. Transparency International. Monograph.

Chakraborty, S., R. Gatti, J. Klugman and G. Gray-Molina. 2002. "When is "Free” Not So Free? Informal Payments for Basic Health Services in Bolivia. Mimeo. Processed.

Chaudhury, N., and J.S. Hammer. 2004. "Ghost Doctors: Absenteeism in Bangladeshi Health Facilities”. World Bank Economic Review 18(3). 
Chaudhury, N., J.S. Hammer, M. Kremer et al. 2004. "Provider Absence in Schools and Health Clinics”. Northeast Universities Development Consortium Conference, HEC Montreal, October.

Chawla, M. 2001. "How Well Does the Health Sector in Georgia Serve the Poor: An Examination of Public and Out-of-Pocket Expenditures on Health”. Washington D.C.: World Bank. Processed.

Chawla, M. 2002. "Poland Informal Payments in Health”. Washington, D.C.: World Bank. Mimeo. PRocessed.

Chawla, M., et al. 1999. "Provision of Ambulatory Health Services in Poland: A Case Study from Krakow.” Social Science and Medicine 58:227-235.

Chawla, M., P. Berman, A. Windak, and M. Kulis. 2001. "The Changing Face of the Health Care Providers Market: A Case Study from Poland”. Processed.

Cohen, J. C. 2002. "Improving Transparency in Pharmaceutical Systems: Strengthening Critical Decision Points against Corruption”. Washington, D.C.: World Bank. Mimeo.

Cohen, J. C. and J.C. Montoya. 2002. "Using Technology to Fight Corruption in Pharmaceutical Purchasing: Lessons Learned from the Chilean Experience" World Bank. Mimeo.

Commission for Africa. 2005. Our Common Interest: Report of the Commission for Africa

Commission on Macroeconomics and Health. 2001. Macroeconomics and Health: Investing in Health for Economic Development. Geneva: World Health Organization.

Das Gupta, M., V. Gauri, and S. Khemani. 2003. "Primary Health Care Service Delivery in Nigeria. Survey Evidence from Lagos and Kogi”. Development Research Group. Washington D.C.: World Bank.

Dehn, J., R.Reinikka, and J. Svensson. 2003. "Survey Tools for Assessing Performance in Service Delivery.” In Francois Bourguignon and Luiz Pereira da Silva, eds., Evaluating the Poverty and Distributional Impact of Economic Policies. Oxford University Press and World Bank.

Delcheva, El, D. Balabanova, and M. McKee. 1997. "Under-the-Counter Payments for Health Care.” Health Policy, 42:89-100.

Di Tella, R. and Savedoff, W. D. (eds.). 2001. Diagnosis Corruption. Washington, DC: Inter-American Development Bank. 
Di Tella, R. and Savedoff, W. D. "Shining Light in Dark Corners.” In Di Tella, R. and Savedoff, W. D. (eds.). 2001. Diagnosis Corruption. Washington, DC: InterAmerican Development Bank.

Eichler, R., P. Auxilia and J. Pollock. 2001. “Output-Based Health Care: Paying for Performance in Haiti.” World Bank, Viewpoint, Note 236. Washington, D.C.

Elliott, K. A. 1997. (Ed). Corruption and the Global Economy. Washington, DC: Institute for International Economics.

Falkingham, J. 2002. "Health, health seeking behavior and out of pocket expenditures in Kyrgyzstan 2001”. Kyrgyz Household Health Finance Survey. London School of Economics. Monograph.

Falkingham, J. 2000. "Poverty, out-of-pocket payments and inequality in access to health care: evidence from Tajikistan”. London School of Economics.

Falkingham, J. 2004. "Poverty, Out-of-Pocket Payments and Access to Health Care: Evidence from Tajikistan.” Social Science and Medicine, 58: 247-258.

Filmer, D. and L. Pritchett. 1999. “ The Impact of Public Spending on Health: Does Money Matter?” Social Science and Medicine. 49; 1309-1323.

Fisman, R., R. Gatti. 2000. "Decentralization and Corruption: Evidence across Countries”. Development Research Group. Washington D.C. World Bank. Processed.

Gatti, R., G. Gray-Molina, and J. Klugman. 2003. "Determinants of Corruption in Local Health Care Provision: Evidence from 108 Municipalities in Bolivia”. World Bank. Processed.

Giedion, U. Morales, L. G. and Acosta, O. L. “The Impact of Health Reforms on Irregularities in Bogotá Hospitals.” In Di Tella, R. and Savedoff, W. D. (eds.). 2001. Diagnosis Corruption. Washington, DC: Inter-American Development Bank.

Gilson, L. 1997. “The Lessons of User Fee Experience in Africa.” Health Policy and Planning 12(4): 273-285

Gopakumar, K. 1998. “Citizen Feedback Surveys to Highlight Corruption in Public Services: the Experience of Public Affairs Centre, Bangalore.” (September) Mimeo.

Gosden, T., L. Pedersen and d. Torgerson. 1999. "How should We Pay Doctors? A Systematic Review of Salary Payments and their Effect on Doctor Behavior" Quarterly Journal of Medicine (92) 47-55. 
Gray-Molina, G., de Rada, E. P. and Yañez, E. "Does Voice Matter? Participation and Controlling Corruption in Bolivian Hospitals.” In Di Tella, R. and Savedoff, W. D. (eds.). 2001. Diagnosis Corruption. Washington, DC: Inter-American Development Bank.

Gray-Molina, G., E. Perez de Rada and E. Yanez. 2001. “Does Voice Matter? Participation and Controlling Corruption in Bolivian Hospitals,” In Diagnosis Corruption Fraud in Latin America's Public Hospitals W. Savedoff and R. Di Tella eds.

Gupta, S., H. Davoodi, and E. Tiongson. 2000. "Corruption and the Provision of Health Care and Education Services”. IMF Working Paper. Washington D.C.: International Monetary Fund.

Hotchkisss, D., P. Hutchinson, A. Malaj and A. Berruti. 2005. "Out-of-pocket Payments and Utilization of Health Care Services in Albania: Evidence from Three Districts.” Health Policy (forthcoming).

Hsiao, W. 2005. Personal communication based on studies in China.

IMF and World Bank. 2005. Global Monitoring Report. Washington, D.C.: International Monetary Fund and World Bank.

IMF. 1997. “Good Governance: The IMF’s Role”. IMF Guidance Note. Washington, D.C.: International Monetary Fund.

Jack, W. and M. Lewis. 2004. "Falling Short of Expectations: Public Health Interventions in Developing and Transition Economies.” Social Science and Medicine 58(2).

Jaén, M. H. and Paravinski, D. "Wages, Capture and Penalties in Venezuela's Public Hospitals.” In Di Tella, R. and Savedoff, W. D. (eds.). 2001. Diagnosis Corruption. Washington, DC: Inter-American Development Bank.

Kaufman , D. and A. Kraay. 2003. Governance and Growth: Causality which way? Evidence for the World, in brief.” Washington, D.C.: World Bank

Kaufman, D, A. Kraay and M. Maztruzzi. 2005. "Governance Matters III: Governance Indicators for 1996-2002.” Washington, D.C.: World Bank.

Kaufman, D, A. Kraay and P. Zoido-Lobatón. 1999. “Governance Matters.” World Bank Policy Research Working Paper 2196. Washington, D.C.: World Bank.

Kaufmann, D. 2003. “On Evidence-based Rethinking of Governance and Challenging Orthodoxy.” Presentation at USAID, Washington, DC, September 23. http://www.worldbank.com/wbi/governance/pdf/usaid_present092303.pdf 
Kaufmann, D. and A. Kraay. 2002. “Growth Without Governance”. Economia 3(1):169215.

Kaufmann, D. and S.-J. Wei. 1999. "Does “Grease Money” Speed Up the Wheels of Commerce?” NBER Working Papers 7093. National Bureau of Economic Research, Inc.

Khemani, S. 2004. "Local Government Accountability for Service Delivery in Nigeria." World Bank. Processed.

Killingsworth, J., N. Hossain, Y. Hedrick-Wong et. al. 1999. "Unofficial Fees in Bangladesh: Price, Equity and Institutional Issues.” Health Policy and Planning, 14(2): 152-163.

Klitgaard, R. 1998. “Strategies against Corruption.” Presentation at Agencia Española de Cooperación Internacional Foro Iberoamericano sobre el Combate a la Corrupción, Santa Cruz de la Sierra, Jun 15-16. http://unpan1.un.org/intradoc/groups/public/documents/clad/clad0035403.pdf

Koenig, M. A., M. A. Khan, B. Wojtyniak, J. D. Clemens, J. Chakraborty, V. Fauveau, J. F. Phillips, J. Akbar, and U.S. Barua. 1991. "Impact of Measles Vaccination on Childhood Mortality in Rural Bangladesh.” Bulletin of the World Health Organization 68(4): 441-447.

Kutzin, J., T. Maeimanaliev, A. Ibraimova, C. Cashin, and S. O’Dougherty. 2003. "Formalizing Informal Payments in Kyrgyz Hospitals: Evidence from Phased Implementation of Financing Reforms.” Paper presented at IHEA Conference, San Francisco, California.

La Forgia, G. 2005. Health System Innovations in Central America: Lessons and Impact of New Approaches. World Bank Working Paper No. 57, Washington, D.C.: World Bank.

La Forgia, G., R. Levine, A. Dias and M. Rathe. 2004. "Fend for Yourself, Systemic Failure in the Dominican Health System. Health Policy 67:173-186.

Leonard, K. 2005. “Getting Clinicians To Do Their Best: Ability, Altruism and Incentives." University of Maryland. Mimeo (Draft)

Lewis, M. 2000. "Who Is Paying for Health care in Europe and Central Asia?” Europe and Central Asia Region. Monograph. Washington D.C.: World Bank.

Lewis, M. 2003. "Health and Corruption in Developing and Transition Countries" Presented at the Transparency International Annual Conference, Seoul, Korea. (May)

Lewis, M. 2005. "Improving Efficiency and Impact in Health Care Services - Lessons from Central America" in Health System Innovations in Central America: 
Lessons and Impact of New Approaches. World Bank Working Paper No. 57, Washington, D.C.: World Bank.

Lewis, M., 2002. "Informal Health Payments in Central and Eastern Europe and the Former Soviet Union: Issues, Trends and Policy Implications" in Funding Health Care: Options for Europe. Figueres and Moussiales. editors. Buckingham: Open University Press.

Lewis, M., G. Eskeland, and X. Traa-Valarezo. 2004. "Effectiveness and Impact of Rural Health Care Policies in El Salvador”. Health Policy. 70(3): 303-325.

Lewis, M., G. La Forgia, and M. Sulvetta. 1992. "Productivity and Quality of Public Hospital Staff: A Dominican Case Study.” International Journal of Health Planning and Management. 6.

Lewis, M., G. La Forgia, and M. Sulvetta. 1996. "Measuring Public Hospital Costs: Empirical Evidence from the Dominican Republic." Social Science and Medicine. 43(2): $221-234$.

Lindelow, M. and J. Dehn. 2001. "Public Expenditure Tracking Survey of the Health Sector in Mozambique”. Washington, D.C.: World Bank. Draft.

Lindelow, M., I. Kushnarova and K. Kaiser. 2005. "Measuring Corruption in the Health Sector: What We Can Learn from Public Expenditure Tracking and Service Delivery Surveys in Developing Countries.” Washington D.C.: World Bank

Lindelow, M., P. Serneels, and T. Lemma. 2003. "Synthesis of Focus Group Discussions with Health Workers in Ethiopia.” Washington, D.C.: World Bank, DEC Draft paper.

Lindelow, M., P. Ward, and N. Zorzi. 2004. "Expenditure Tracking and Service Delivery Survey”, The Health Sector in Mozambique”. Final Report. Washington D.C.: World Bank. Processed.

Lindelow, M., Reinikka R., and Svensson J. 2003. "Health Care on the Frontlines. Survey Evidence on Public and Private Providers in Uganda”. Africa Region Human Development Working Paper Series. Washington D.C.: World Bank. Forthcoming.

McPake, B.,A. D. Asiimwe, F.Mwesigye, et. al. 1999. "Informal Economic Activities of Public Health Workers in Uganda: Implications for Quality and Accessibility of Care.” Social Science and Medicine. 49: 849-865

Murrugarra E., and Cnobloch, R. 2003. "Health Status and Health Care Dimensions of Poverty in Armenia”. Europe and Central Asia Region, Human Development Department. Washington D.C.: World Bank. Processed. 
Narayan, D. 2000. Voices of the Poor. Washington, D.C.: World Bank and Oxford University Press.

Partnership for Governance Reform. 2002. A Diagnostic Study of Corruption in Indonesia.

Phongpaichit, P., N. Treerat, Y. Chaiyapong, and C. Baker. 2000. "Corruption in the Public Sector in Thailand Perceptions and Experience of Households. Report of a nationwide survey”. Political Economy Centre. Bangkok.: Chulalongkorn University. Processed.

Rajkumar, A. S. and V. Swaroop 2002. "Public Spending and Outcomes: Does Governance Matter?” Policy Research Working Paper Series 2840. Washington D.C.: World Bank.

Rauch, J. E. and P. B. Evans. 2000. "Bureaucratic Structure and Bureaucratic Performance in Less Developed Countries.” Journal of Public Economics 75(1): 49-71.

Reinikka R and Svensson J. 2003. "Working for God? Evaluating service delivery of religious not-for-profit health care providers in Uganda” World Bank Policy Research Working Paper 3058 (May).

Reinikka R and Svensson J. 2004. "The Power of Information: Evidence from a Newspaper Campaign to Reduce Capture.” Mimeo (March).

Reinikka R. and J. Svensson. 2002. "Measuring and Understanding Corruption at the Micro Level.” Mimeo (January) Processed.

Reinikka, R. and J. Svensson. 2004. "Local Capture: Evidence from a Central Government Transfer Program in Uganda.” Quarterly Journal of Economics 119(2): 679-705.

Rigobon, R. and D. Rodrik. 2004. "Rule of Law, Democracy, Openness and Income: Estimating the Interrelationships.” NBER Working Papers 10750. National Bureau of Economic Research, Inc.

Rodrik, R., A. Subramanian and F. Trebbi. 2002. "Institutions Rule: The Primacy of Institutions over Geography and Integration in Economic Development.” NBER Working Papers 9305. National Bureau of Economic Research, Inc.

Roland, M. 2004. "Linking Physician's Pay to the Quality of Care - A Major Experiment in the UK.” New England Journal of Medicine 351(14): 1448-1458.

Ryterman, J., J. Hellman and G. Jones et al., 2000. "Corruption in Russia: Interim Report.” World Bank. Mimeo (June) Processed. 
Sari, A., J. Langenbrunner, and M. Lewis. 2000. "Affording Out-of-Pocket Payments for Health Care Services: Evidence from Kazakhstan.” Euroheath 6,2 (Spring). Geneva: World Health Organization.

Schargrodsky, E., Mera, J. and Weinschelbaum, F. “Transparency and Accountability in Argentina's Hospitals.” In Di Tella, R. and Savedoff, W. D. (eds.). 2001. Diagnosis Corruption. Washington, DC: Inter-American Development Bank.

Shahriari, H., P. Belli, and M. Lewis. 2001. "Institutional Issues in Informal Health Payments in Poland: Report on the Qualitative Part of the Study”. HNP Working Paper. Washington D.C.: World Bank.

Shishkin, Sergey. 2003. “Informal Payments for Health Care in Russia”. Presentation at IHEA $20034^{\text {th }}$ World Congress, San Francisco. Processed.

Shleifer, A. and R. W. Vishny. 1993. “Corruption.” Quarterly Journal of Economics 108(3): 599-617.

Soto, B. 2002. "Corruption and the Colombian Health System Reform.” Corruption in Health Services. WHO/I-ADB/Transparency International Report. Mimeo.

Sparrow, M. (1996). License to Steal: Why Fraud Plagues the American Health Care System. Boulder, Colorado: Westview Press.

Stempovscaia, E. 2002. "Corruption in the Public Health Service in a Post-Communist Country: Some Elements of corruption in the Transition Period in Moldova.” In Corruption in Health Services. WHO/IDB/Transparency International Report.

Tendler, J. and S. Freedheim. 1994. "Trust in a Rent- Seeking World: Health and Government Transformed in Northeast Brazil.” World Development 22(12): 1771-1791.

Thampi, G.K. 2002. Corruption in South Asia, Insights \& Benchmarks from Citizen Feedback Surveys in Five Countries. Monograph.

Thamrin, Jalan M.H. 2002. “A Diagnostic Study of Corruption in Indonesia”. Partnership for Governance Reform in Indonesia. Final Report. Processed.

Thompson, R. 2004. Informal Payments for Emergency Hospital Care in Kazakhstan: An Exploration of Patient and Physician Behavior. Ph.D. thesis. York, UK: University of York.

Thompson, R. and A. Xavier. 2002. "Unofficial Payments for Acute State Hospital Care in Kazakhstan. A Model of Physician Behavior with Price Discrimination and Vertical Service Differentiation”. LICOS Centre for Transition Economics. LICOS Discussion Papers.

Transparency International. 2003. Global Corruption Report 2003. 
Transparency International. 2005. Global Corruption Report 2005.

United Nations Millennium Project. 2005. Investing in Development: A Practical Plan to Achieve the Millennium Development Goals. Sterling: Earthscan.

Van Rijckeghem, C. and B. Weder. 2001. "Bureaucratic Corruption and the Rate of Temptation: Do Wages in the Civil Service Affect Corruption and by How Much? Journal of Development Economics (65) 307-331.

Vitosha/USAID, 2002. "Regional Corruption Monitoring in Albania, Bosnia and Herzegovina, Bulgaria, Croatia, Macedonia, Romania, and Yugoslavia”. Mimeo. Processed.

Wagstaff, A. and M. Claeson. 2004. Rising to the Challenge: The Millennium Development Goals for Health. Washington, D.C.: World Bank.

World Bank 2000c. "Paraguay: Resultados de los Diagnosticos a Funcionarios Publicos y Ususarios de los Servicios”. Washington D.C.: World Bank. Processed.

World Bank 2001a. "Voices of the Misgoverned and Misruled: An Empirical Diagnostic Study on Governance, Rule of Law and Corruption for Peru". Washington D.C.: World Bank. Processed.

World Bank. 1997. World Development Report. The State in a Changing World. Washington, D.C.: World Bank.

World Bank. 2000a, “Armenia Institutional and Governance Review”. World Bank Report. Washington D.C.: World Bank. Processed.

World Bank. 2000b. "Cambodia Governance and Corruption Diagnostic: Evidence from Citizen, Enterprise and Public Official Survey”.. World Bank Report. Washington D.C.: World Bank. Processed.

World Bank. 2000d. "The Ghana Governance and Corruption Survey, Evidence from Households, Enterprises and Public Officials. Africa Region”. Washington D.C.: World Bank. Processed.

World Bank. 2001b. "Voice of the Poor and Taming of the Shrew: Evidence from the Bolivia Public Officials’ Survey”. Latin America and Caribbean Region. Washington D.C.: World Bank. Processed.

World Bank. 2001c. "Kazakhstan Governance and Service Delivery: A Diagnostic Report”. Poverty Reduction and Economic Management Unit, Europe and Central Asia Region. Washington D.C.: World Bank. Processed.

World Bank. 2001d. "Diagnostic Survey of Corruption in Romania”. Washington D.C.: World Bank. Processed. 
World Bank. 2001e. “Bosnia and Herzegovina Diagnostic Surveys of Corruption”. Washington D.C.: World Bank. Processed.

World Bank. 2001f. "Honduras: Public Expenditure Management for Poverty Reduction and Fiscal Sustainability.” Report No. 22070. Washington D.C.: World Bank.

World Bank. 2002a. “A Strategy to Combat Corruption in the ECA Region”. Issues Paper and Progress Report. Washington D.C.: World Bank. Processed.

World Bank. 2002b. "Governance and Service Delivery in the Kyrgyz Republic - Results of Diagnostic Surveys”. Poverty Reduction and Economic Management Unit, Europe and Central Asia Region. Washington D.C.: World Bank. Processed.

World Bank. 2003a. “Albania: Poverty Assessment”. Europe and Central Asia Region. Washington D.C.: World Bank.

World Bank. 2003b. Better Governance for Development in the Middle East and North Africa: Enhancing Inclusiveness and Accountability. Washington, D.C.: World Bank

World Bank. 2003c. Turkey: Reforming the Health Sector for Improved Access and Efficiency. Report No. 24358-TU. Washington, D.C.: World Bank.

World Bank. 2004a. World Development Report. Making Services Work for Poor People. Washington, D.C.: World Bank.

World Bank. 2004b. Ethiopia: A Country Status Report. Report No. 28963-ET. Washington, D.C.: World Bank.

World Bank. 2004c. The Millennium Development Goals for Health: Rising to the Challenge. Washington, D.C.: World Bank.

World Bank. 2005a. Doing Business in 2005: Removing Obstacles to Growth. Washington, D.C.: World Bank.

World Bank. 2005b. Ethiopia: A Country Status Report on Health and Poverty. Washington, D.C.: World Bank.

World Bank. 2006. World Development Report. Equity and Development. Washington, D.C.: World Bank.

World Bank. Forthcoming. Nigeria: Health, Nutrition and Population: Country Status Report. Washington D.C.: World Bank Draft. 


\section{Source Appendix 1: Figures 4 and 5}

\begin{tabular}{|c|c|}
\hline Country & Data Year \\
\hline Albania & 2002 \\
\hline Albania & 2002 \\
\hline Armenia & 2001 \\
\hline Bangladesh & 2002 \\
\hline Bolivia & 2001 \\
\hline Bosnia & 2000 \\
\hline Bosnia & 2002 \\
\hline Bulgaria & 2001 \\
\hline Bulgaria & 2002 \\
\hline Cambodia & 1999 \\
\hline China & n.d. \\
\hline Colombia & n.d. \\
\hline Croatia & 2002 \\
\hline Czech Republic & 2002 \\
\hline Georgia & 2000 \\
\hline Ghana & 1998 \\
\hline Ghana & 2000 \\
\hline Hungary & 2002 \\
\hline India & 2002 \\
\hline Indonesia & 2001 \\
\hline Khazakhstan & 2001 \\
\hline Kosovo & 2000 \\
\hline Krygyz & 2001 \\
\hline Kyrgyz & 2001 \\
\hline Latvia & 1998 \\
\hline Macedonia & 2002 \\
\hline Madagascar & 2001 \\
\hline Moldova & 2000 \\
\hline Moldova & 2002 \\
\hline Morroco & 2001 \\
\hline Nepal & 2002 \\
\hline Pakistan & 2002 \\
\hline Paraguay & 1999 \\
\hline Peru & 2001 \\
\hline Poland & 1998 \\
\hline Romania & 2000 \\
\hline Romania & 2002 \\
\hline Russia & 2002 \\
\hline Senegal & 2001 \\
\hline Serbia & 2002 \\
\hline Slovakia & 2000 \\
\hline Sri Lanka & 2001 \\
\hline Tajikistan & 1999 \\
\hline Tajikistan & 2001 \\
\hline Thailand & 1999 \\
\hline Vietnam & 1998 \\
\hline Uzkbekistan & 2001 \\
\hline
\end{tabular}

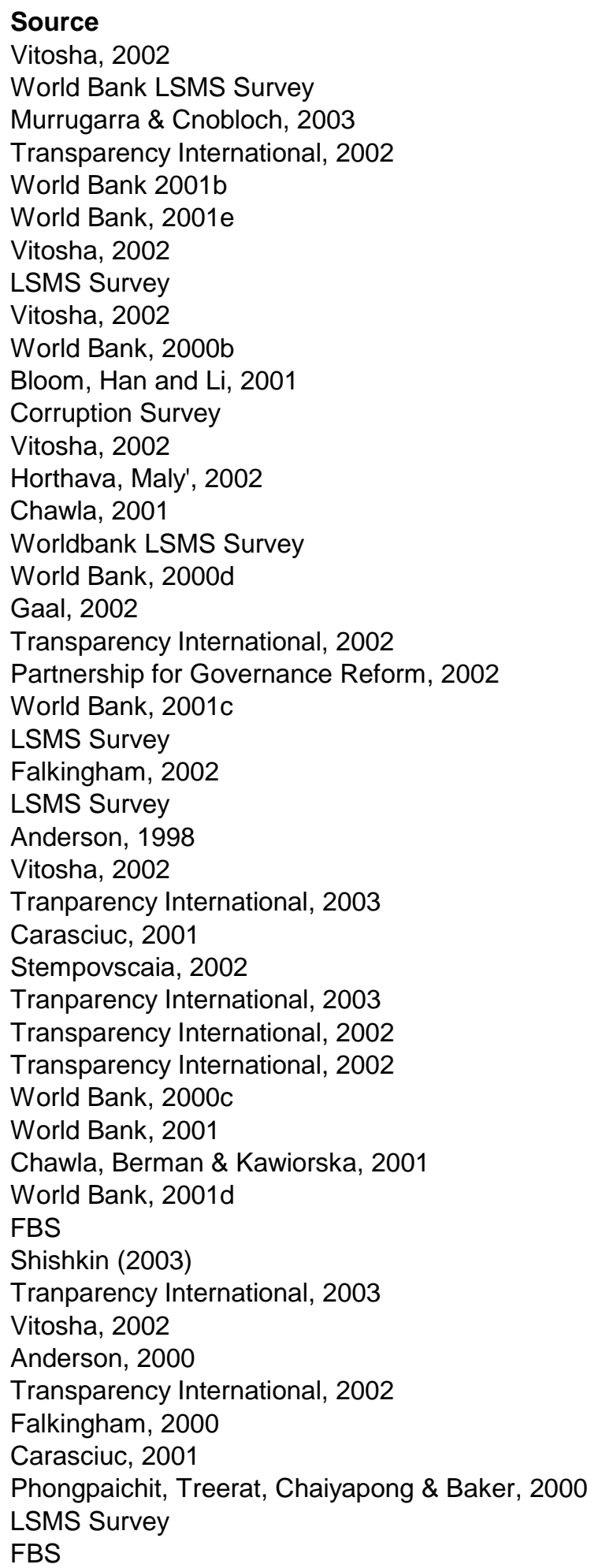

